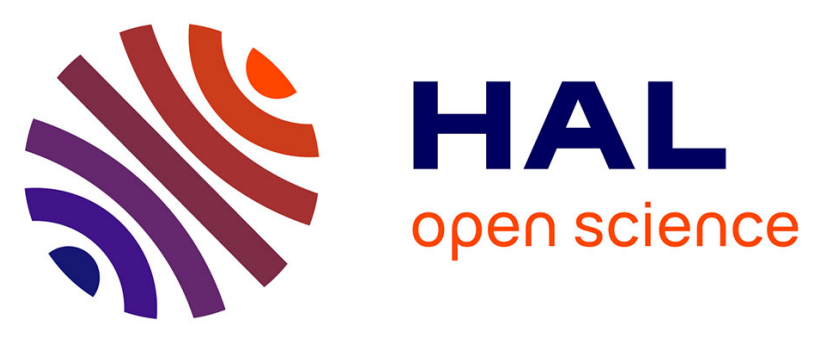

\title{
Virtually Transparent TiO2/Polyelectrolyte Thin Multilayer Films as High Efficiency Nanoporous Photocatalytic Coatings for Breaking Down Formic Acid and for E. Coli Removal
}

María Guadalupe Méndez-Medrano, Marvin Motay, David Martel, Bertrand Vileno, Charline Soraru, Lydie Ploux, María Guadalupe Méndez-Medrano, Christophe Colbeau-Justin, Gero Decher, Nicolas Keller

\section{- To cite this version:}

María Guadalupe Méndez-Medrano, Marvin Motay, David Martel, Bertrand Vileno, Charline Soraru, et al.. Virtually Transparent TiO2/Polyelectrolyte Thin Multilayer Films as High Efficiency Nanoporous Photocatalytic Coatings for Breaking Down Formic Acid and for E. Coli Removal. ACS Applied Materials \& Interfaces, 2020, 12 (50), pp.55766-55781. 10.1021/acsami.0c13545 . hal03093311

\author{
HAL Id: hal-03093311 \\ https://hal.science/hal-03093311
}

Submitted on 3 Jan 2021

HAL is a multi-disciplinary open access archive for the deposit and dissemination of scientific research documents, whether they are published or not. The documents may come from teaching and research institutions in France or abroad, or from public or private research centers.
L'archive ouverte pluridisciplinaire HAL, est destinée au dépôt et à la diffusion de documents scientifiques de niveau recherche, publiés ou non, émanant des établissements d'enseignement et de recherche français ou étrangers, des laboratoires publics ou privés. 


\section{Virtually Transparent $\mathrm{TiO}_{2} /$ Polyelectrolyte Thin}

\section{Multilayer Films as High Efficiency Nanoporous}

\section{Photocatalytic Coatings for Breaking Down}

\section{Formic Acid and for E. Coli Removal}

Marvin Motay ${ }^{a, b}$ David Martel, ${ }^{b}$ Bertrand Vileno, ${ }^{c}$ Charline Soraru, ${ }^{d}$ Lydie Ploux, ${ }^{d, e}$ María Guadalupe Méndez-Medrano, ${ }^{f}$ Christophe Colbeau-Justin, ${ }^{f}$ Gero Decher, ${ }^{b}$ Nicolas Keller ${ }^{a, *}$

${ }^{a}$ Institut de Chimie et Procédés pour l'Energie, l'Environnement et la Santé (ICPEES), CNRS, Université de Strasbourg, 25 rue Becquerel 67087 Strasbourg, France

b Institut Charles Sadron (UPR 22), CNRS, Université de Strasbourg, 23 rue de Loess, 67034, Strasbourg Cedex 2, France

c Institut de Chimie, CNRS, Université de Strasbourg, CNRS, 1 rue Blaise Pascal 67008 Strasbourg Cedex, France

${ }^{\mathrm{d}}$ Institut de Science des Matériaux de Mulhouse (IS2M, UMR7361 CNRS/Université de Haute Alsace), 15 rue Jean Starcky, 68057 Mulhouse, France

${ }^{\mathrm{e}}$ Biomaterial Bioengineering (U1121 INSERM/Université de Strasbourg), 11 rue Humann, 67000 Strasbourg, France

${ }^{\mathrm{f}}$ Institut de Chimie, CNRS UMR 8000, Université Paris-Saclay, 91405 Orsay, France corresponding author: *nkeller@unistra.fr 
KEYWORDS. Layer-by-Layer assembled films ; $\mathrm{TiO}_{2}$ nanoparticles ; photocatalytic coatings; quantum yield ; formic acid mineralization ; antibacterial properties.

\section{ABSTRACT.}

Virtually transparent photocatalytic multilayer films composed of $\mathrm{TiO}_{2}$ nanoparticles and polyelectrolytes were built on model surfaces using layer-by-layer assembly and investigated as photocatalytic nanoporous coatings. Formic acid $(\mathrm{HCOOH})$ and Escherichia coli were used as models for the degradation of gaseous pollutants and for studying antibacterial properties. Positively charged $\mathrm{TiO}_{2}$ nanoparticles were co-assembled with negatively charged poly (sodium 4-styrenesulfonate) (NaPSS) which leads to highly transparent nanoscale coatings in which the content of $\mathrm{TiO}_{2}$ particles is controlled mainly by the number of deposition cycles and the enhanced translucency with respect to titania powders is likely due to the presence of the polyelectrolytes in the interstitial space between the particles. Build-up and structural properties of the films were determined by ellipsometry, Quartz Crystal Microbalance (QCM-D, with dissipation monitoring), UV-Vis spectrophotometry in transmission and scanning electron microscopy. Complementary photophysical and activity tests of $\left(\mathrm{PSS} / \mathrm{TiO}_{2}\right)_{\mathrm{n}}$ multilayer films were performed in the gas-phase under UV-A light and revealed a peculiar dependence on the number of layer pairs, corresponding to a clear deviation from the usual observations in photocatalysis with increasing $\mathrm{TiO}_{2}$ amounts. Most notably, a single layer pair film showed a strongly enhanced $\mathrm{HCOOH}$ mineralization and outperformed films with a higher number of layer pairs, with respect to the quantity of $\mathrm{TiO}_{2}$ catalyst present in the films. It is believed that the high quantum yield (8.1\%) of a coating consisting of a single $\mathrm{TiO}_{2}$ layer which is 6-7 times higher than that of a film consisting of 6-10 layer pairs could be due to the optimum accessibility of the $\mathrm{TiO}_{2}$ crystallites towards both $\mathrm{HCOOH}$ and water molecules. In thicker films, while no detrimental light screening was observed with increasing the number of layer pairs, diffusion 
phenomena could cap the efficiency of the access of the pollutant and water to the catalytic surface. Unlike for $\mathrm{HCOOH}$ mineralization, three $\mathrm{PSS} / \mathrm{TiO}_{2}$ layer pairs were required for observing a maximum antibacterial activity of the nanocomposite coatings. This is likely due to the fact that micron-size E.coli bacteria do not enter into the interstitial space between the $\mathrm{TiO}_{2}$ particles and require a different surface morphology with respect to the number of active contact points for an optimum degradation. 


\section{INTRODUCTION}

Heterogeneous photocatalysis gained importance in the last decades for facing new challenges and addressing major societal concerns on environment, sustainable chemistry and energy demand. ${ }^{1,2}$ Up to now, wide band-gap titanium dioxide $\left(\mathrm{TiO}_{2}\right)$ remains the most efficient single-phase photocatalyst when exposed to artificial or natural UV-A light for the implementation of photoactive surfaces or the development of environmental remediation technologies for purifying air or water. ${ }^{3,4,5,6}$ Therefore, the immobilization of $\mathrm{TiO}_{2}$ in thin photocatalytic coatings found growing attention, either for elaborating self-cleaning surfaces or for being stabilized into photocatalytic reactors. ${ }^{7,89}$ Among many bottom-up-type methods such as e.g. sol-gel synthesis or chemical/physical vapor deposition, the self-assembly approach in which molecules and/or particles assemble themselves without the presence of outside interactions, is very promising. ${ }^{10}$

Layer-by-Layer (LbL) is a scalable technology for building high-quality solution-processed nano-composite films from a large choice of different components. ${ }^{11,12,13}$ This versatile technique enables the development of function-specific multilayer assemblies for providing new or complementary properties to substrates, through the alternate deposition of oppositelycharged materials on charged surfaces. First applied for preparing polyelectrolyte multilayers, LbL assembly is a simple yet powerful process for preparing multi-material films with tunable properties, and has consequently been extended to many other charged components for building sandwich-like superstructures..$^{14,15,16,17,18}$

LbL assembly has the advantage that it can be applied on model surfaces for a controlled monitoring of for example film growth or for a more detailed understanding of the film properties. In addition it can also be used for forming highly similar coatings at identical 
deposition conditions on more complex, irregular surfaces that suffer from a lack of characterization methods. This way the deposition can be optimized using structural data from model surfaces (for example quartz slides or Si-wafers) while the performance data of a nanocomposite material are obtained from application-relevant substrates (for example textiles). Another advantage arises from the fact that the "soft" self-assembly conditions allow for preparing stable photocatalytic coatings on mechanically fragile or thermally sensitive surfaces.

The past years have brought an increasing number of applications of the LbL self-assembly method in a large variety of fields, among which the photocatalytic applications are an especially fast-developing area as multilayer films are often transparent, whether environmental remediation, self-cleaning/decontaminating or hydrogen production applications are concerned. ${ }^{13,19,20,21,22,23,24,25,26,27}$ Further, the amphoteric properties of most of the photocatalytic materials (eg. titania) favors its versatile incorporation within multilayer films, by allowing negatively or positively-charged titania suspensions to be prepared by suitably adjusting the $\mathrm{pH}$ acidic or alkaline media. ${ }^{13,28}$

Some of the recent investigations of photocatalytic LbL films concern the gas phase heterogeneous photocatalytic oxidation for the mineralization of air pollutant such as 2propanol, ${ }^{29,30}$ acetaldehyde, ${ }^{31}$ hydrogen sulfide ${ }^{32}$ or ammonia, ${ }^{33}$ as well as chloroethyl ethyl sulfide as model of chemical warfare agents. ${ }^{34}$ The elaboration of antibacterial photocatalytic surfaces has also been studied for developing self-disinfecting textiles. ${ }^{22}$

Here we report on the development of homogeneous, nano-porous and virtually optically transparent LbL thin films containing Aeroxide ${ }^{\circledR} \mathrm{TiO}_{2} \mathrm{P} 25$ nanoparticles - currently the defacto commercial reference photocatalyst ${ }^{35,36}$ - with photocatalytic activity under UV-A light in both gas phase degradation of formic acid and Escherichia coli (E. coli) bacteria inactivation. We demonstrate here the peculiar photocatalytic behavior of the films with regard to the layer number, that deviates from the usual trend observed in photocatalysis with increasing the 
photocatalyst amount, and we consequently discussed on the high $\mathrm{HCOOH}$ mineralization and quantum yields obtained on the film built with only one single layer pair. E. coli bacteria was used for assessing the antibacterial efficiency of the films, since this very-well documented bacteria can be identified as causing microbial problems in a variety of contexts. Indeed, many of them are responsible for infections, with detrimental consequences resulting from their population growth, due to either their pathogenicity or the imbalance of a microbiological ecosystem leading to excessive growth of a commensal population. Formic acid ( $\mathrm{HCOOH})$ was taken as gas phase model compound for assessing the photocatalytic activity and the behavior of the multilayer films towards gaseous chemical pollution, although it is not considered as one of the main encountered Volatile Organic Compounds (VOCs). Indeed, $\mathrm{HCOOH}$ is the main reaction intermediate formed during the photocatalytic oxidation of formaldehyde (one of the most problematic VOCs from indoor air), and the ultimate reaction intermediate observed in the photocatalytic degradation of many VOCs like acetone or 2-butanone. Also, formic acid can be directly mineralised into water and carbon dioxide without the formation of any longlived gaseous intermediates. ${ }^{5,37}$ In addition, $\mathrm{HCOOH}$ by-itself can give rise to irritation and tissues and organs with high oxygen consumption are vulnerable to $\mathrm{HCOOH}$ exposures. ${ }^{38}$

\section{EXPERIMENTAL}

\subsection{Materials and substrates}

Aeroxide ${ }^{\circledR}$ titanium dioxide $\left(\mathrm{TiO}_{2}\right) \mathrm{P} 25$ was provided by Evonik (Germany) as a fine powder. Poly(ethyleneimine) (PEI, $\mathrm{M}_{\mathrm{w}} \approx 750000 \mathrm{~g} / \mathrm{mol}, 50$ wt. \% in water), Poly(sodium 4styrenesulfonate) (PSS, Mw $\approx 70000 \mathrm{~g} / \mathrm{mol}$ ) and Poly(diallyldimethyliammonium chloride) (PDDA, Mw $\approx 100000-200000 \mathrm{~g} / \mathrm{mol}, 20 \mathrm{wt} . \%$ in water) were purchased from Sigma Aldrich. 
Nitric acid $\left(\mathrm{HNO}_{3}\right) 68 \%$ and Formic acid $(\mathrm{HCOOH}$, reagent grade $>95 \%)$ were bought from Prolabo and Sigma-Aldrich, respectively. Milli-Q water (ultrapure water) with a resistivity of 18.2 M .cm was obtained from a Milli-Q gradient (Millipore, France) at $25^{\circ} \mathrm{C}$. Hellmanex III (Hellma Analytics) was purchased from Sigma Aldrich. Ethanol (99.5\% absolute anhydrous) was bought from Carlo Erba.

Silicon wafers with an orientation of $<100>$ were purchased from WaferNet INC (San José, CA, USA). Glass (microscope) slides were purchased from Roth (Germany). $1 \mathrm{~mm}$ thickness quartz slides (Suprasil) were purchased from Thuet B. France (Blodelsheim, France). Gold coated quartz crystals (AT-cut quartz crystals with a $5 \mathrm{MHz}$ fundamental frequency) used for QCM-D characterisations, were purchased from Q-sense - Biolin Scientific (Sweden). The preparation of the different substrates has been described in Supporting Information SI1.

\subsection{Preparation of polyelectrolyte solutions and suspensions}

Positively-charged poly(ethylene imine) (PEI) solution was prepared at a concentration of 1 $\mathrm{g} \cdot \mathrm{L}^{-1}$ in Milli-Q water. Negatively-charged poly(sodium 4-styrenesulfonate) (NaPSS) solution was prepared at a concentration of $1 \mathrm{~g} \cdot \mathrm{L}^{-1}$ in Milli-Q water at $\mathrm{pH} 2.5$ (adjusted by $\mathrm{HNO}_{3}$ ).

Since $\mathrm{TiO}_{2}$ has amphoteric properties due to its surface groups $\left(\mathrm{TiOH}_{2}{ }^{+}\right.$or $\mathrm{TiO}^{-}$respectively in acidic or alkaline media), negatively or positively-charged suspensions can be prepared by adjusting the $\mathrm{pH} \cdot{ }^{13,28} 2 \mathrm{~g}$ of $\mathrm{TiO}_{2}$ were added to $80 \mathrm{~mL}$ Milli-Q water with $\mathrm{pH} 2.5$ (adjusted by $\mathrm{HNO}_{3}$ ) and stirred for $1 \mathrm{~h}$. The positively-charged $\mathrm{TiO}_{2}$ suspension obtained at $25 \mathrm{~g} . \mathrm{L}^{-1}$ was then sonicated using a tip-sonicator at a $300 \mathrm{~W}$ power for $25 \mathrm{~min}$ in order to prevent as much aggregation as possible. The suspension was cooled down to room temperature and centrifugated at $3700 \mathrm{rpm}$ for $15 \mathrm{~min}$ to collect only the smallest aggregates. The remaining suspension was $12.25 \pm 0.21 \mathrm{~g} \cdot \mathrm{L}^{-1}$ (value obtained by ICP-AES) and had a milky white colour. The $\mathrm{pH}$ of the suspensions was checked prior to the film constructions. 


\subsection{Multilayered thin film construction by Layer-by-Layer deposition}

Layer-by-Layer (LbL) assembly was performed by the immersion of substrates (“dipping”) in solutions successively depositing oppositely-charged compounds on the model substrates. Positively-charged PEI was used as an adhesion promotor to facilitate the deposition of the first layer on different substrates, and negatively-charged PSS was further deposited on the PEI layer for acting as a glue between consecutively deposited $\mathrm{TiO}_{2}$ layers. In order to preserve the $\mathrm{TiO}_{2}$ positive surface charges, PSS was dissolved in acidic milli-Q water at $\mathrm{pH} 2.5$ adjusted by $\mathrm{HNO}_{3}$.

Once activated by an oxygen plasma, the silicon wafer substrate $(4.5 \times 8 \mathrm{~cm})$ is immerged in the positively-charged PEI solution at 1 g. $\mathrm{L}^{-1}$ for $20 \mathrm{~min}$ and rinsed by three successive $3 \mathrm{~min}$ long immersions in Milli-Q water for $3 \mathrm{~min}$. Due to overcompensation of charges, the substrate surface was positively charged. After being dried by compressed air, the substrate was dipped in the negatively-charged PSS solution for $20 \mathrm{~min}$. The substrate was then rinsed 3 times in acidic Milli-Q water at $\mathrm{pH} 2.5$ for 3 min and dried with compressed air. In the same way as previously stated, the substrate was immersed in the positively-charged $\mathrm{TiO}_{2}$ suspension, rinsed in acidic Milli-Q water and dried with compressed air. The substrate surface was positively charged and the $\left(\mathrm{PSS} / \mathrm{TiO}_{2}\right)$ pair of layers was constructed. The PSS and $\mathrm{TiO}_{2}$ deposition steps were repeated until the desired number of pairs of layers was reached. Films were labelled as $\mathrm{PEI} /\left(\mathrm{PSS} / \mathrm{TiO}_{2}\right)_{\mathrm{n}}, \mathrm{n}$ being the number of layer pairs deposited.

\subsection{Characterization methods}

The amount of titanium in the $\mathrm{TiO}_{2}$ suspensions and in the LbL films was obtained by Inductively Coupled Plasma - Atomic Emission Spectroscopy (ICP-AES). The X-ray diffraction (XRD) patterns of the samples were recorded on a D8 Advance Brucker powder diffractometer in a $\theta / \theta$ mode using the $\mathrm{Cu} \mathrm{K} \alpha_{1}$ radiation at $1.5406 \AA$. 
Top-view Scanning Electron Microscopy (SEM) images were recorded on JEOL JSM-6700 F FEG microscope with an acceleration voltage of $3 \mathrm{kV}$. Hitachi SU8010 microscope was used for characterising the cross sections of titania and polyelectrolytes LbL films with an acceleration voltage of $10 \mathrm{kV}$. The films were cut by a cross section polisher IM4000Plus (Hitachi) using Ar beam and acceleration tension of $6 \mathrm{KeV}$.

Dynamic Light Scattering (DLS) measurements were done on a Zetasizer NanoZS device (Malvern Instrument Ltd, UK) at a scattering angle of $173^{\circ}$ and a wavelength of $632.8 \mathrm{~nm}$ (He/Ne laser) at $25^{\circ} \mathrm{C}$. The analyses were triplicated and the cuvettes were rinsed with Milli-Q water and acidic Milli-Q water $\left(\mathrm{pH} 2.5, \mathrm{HNO}_{3}\right)$ prior to introduction of the $\mathrm{TiO}_{2}$ suspension.

Ellipsometry. Ellipsometric measurements of the LbL films were performed using a PLASMOS SD 2300 ellipsometer operating at the single wavelength of $632.8 \mathrm{~nm}$ and a constant angle of $70^{\circ}$ for monitoring the film construction on silicon wafers and for estimating the film thickness. ${ }^{39}$ A constant refractive index of the films equal to that of $\mathrm{SiO}_{2}(1.465)$ was assumed due to the difficulty of determining the refractive index independently especially with respect to for small layer numbers. Each film thickness was obtained by measuring 10 different point areas randomly selected all along the surface of the Si wafer, and the error bars were the standard deviations of these measurements (including the error bar resulting from each measurement as well), providing indications on the film thickness homogeneity.

\section{Quartz Crystal Microbalance with Dissipation monitoring (QCM-D) measurement.} QCM-D measurements were carried out on the LbL films in a QCM-D E4 (Q-Sense AB, Sweden) using flow modules in parallel. In situ $\mathrm{LbL}$ assemblies of $\mathrm{TiO}_{2}$ nanoparticles and polyelectrolytes were done in a similar manner to those on macroscopic silicon or glass/quartz substrates except that for QCM-D, the LbL assembly was done in parallel (detailed protocol in Supporting Information SI2). Upon the excitation of the crystal at the fundamental frequency of $5 \mathrm{MHz}$, the resonance frequency increase observed at the fundamental as well as the overtone 
frequencies is associated with the increase in hydrodynamic mass deposited onto the crystal surface during the film assembly through the Sauerbrey equation. ${ }^{40}$ Energy dissipation due to viscoelastic film adsorption is reflected by the change in dissipation factor, defined as the ratio between the energy dissipated and stored in the crystal during a single oscillation. In this work, the QCM slide had a proportionality coefficient of $17.7 \mathrm{ng} /\left(\mathrm{cm}^{2} \bullet \mathrm{Hz}\right)$ and calculations were made at the $3^{\text {rd }}, 5^{\text {th }}$ and $7^{\text {th }}$ overtone, considering that the observation from the fundamental frequency is usually not used as it tends to be subjected to artifacts from the sensor clamp. ${ }^{41}$

UV-vis spectrophotometry. UV-visible spectrophotometry was performed on LbL films in the transmission mode using quartz slides $(2.5 \times 4.5 \mathrm{~cm})$ as substrates in a UV-Visible Varian ${ }^{\circledR}$ 100 Scan spectrophotometer. Plasma treatment was applied on both sides of the quartz slide so that polyelectrolytes and titania layers were coated evenly on both sides, and 6 layers of $\mathrm{TiO}_{2}$ were deposited on each side of the quartz slide before reaching signal saturation in the UV-C region, corresponding to $12 \mathrm{PSS} / \mathrm{TiO}_{2}$ layer pairs in total. The absorbance measured after each deposition step was therefore divided by two, for obtaining the absorbance increment corresponding to a single layer pair $\mathrm{PSS} / \mathrm{TiO}_{2}$ deposited and globally for measuring the absorbance of the PEI/(PSS/TiO $)_{n}$ films. Supporting Information SI3 shows the methodology used for estimating the mass of catalyst deposited per layer per surface area.

Time Resolved Microwave Conductivity (TRMC). The charge-carrier lifetimes in the LbL films upon UV illumination were determined by microwave absorption experiments using the TRMC method. ${ }^{42}$ This technique, already used to characterized $\mathrm{TiO}_{2}$ based semiconductors, ${ }^{43,44}$ is based on the measurement of the change of the microwave power reflected by a sample, induced by its laser pulsed illumination. This relative variation of microwave absorption can be correlated, for small perturbations of conductivity, to the variation of sample conductivity. In the case of $\mathrm{TiO}_{2}$, the TRMC signal can be attributed to free electrons created in the band gap. 
The incident microwaves were generated by a Gunn diode of the $\mathrm{K}_{\alpha}$ band at $30 \mathrm{GHz}$. Pulsed light source was an OPO laser (EKSPLA, NT342B) tunable from 225 to $2000 \mathrm{~nm}$. It delivers 8 ns fwmh pulses with a frequency of $10 \mathrm{~Hz}$. The light energy density received by the sample was $1.3 \mathrm{~mJ} \mathrm{~cm}^{-2}$ at $350 \mathrm{~nm}$. The main data provided by TRMC are the maximum value of the signal $\left(I_{\max }\right)$, which indicates the number of the excess charge carriers created by the pulse, including decay processes during the excitation by the laser (10 ns), and the decay $(I(t))$ due to the decrease of the excess electrons, either by recombination or by trapping processes. Concerning the decay, i.e. the lifetime of charge carriers, a short and a long range is usually analysed. The shortrange decay, arbitrarily fixed up to $40 \mathrm{~ns}$ after the beginning of the pulse, represented by the $I_{40 n s} / I_{\max }$ ratio, reflects fast processes, mainly recombination of charge carriers, a high value indicating a low recombination speed. Details can be found in Supporting Information SI4.

Electron Paramagnetic Resonance (EPR). EPR investigations were performed on the LbL films on a continuous-wave EPR X-band spectrometer (EMXplus from Bruker Biospin GmbH, Germany) equipped with a high-sensitivity resonator (4119HS-W1, Bruker). This setup was used to record conventional field-swept spectra of functionalized capillaries filled with aqueous solutions supplemented by spin scavenger molecules (TEMPOL, 4-hydroxy-2,2,6,6tetramethylpiperidine 1-oxyl, Aldrich). Measurements were performed in short intervals between subsequent irradiation periods of $30 \mathrm{~s}$. The principal experimental parameters values were a modulation amplitude of $0.5 \mathrm{G}$, a microwave power of $1.8 \mathrm{~mW}$, a time constant of $c a$. $20 \mathrm{~ms}$ and a conversion time of $c a .50 \mathrm{~ms} .120 \mathrm{G}$ were swept in $60 \mathrm{~s}$ per scan recorded after each illumination step. The film construction inside the glass capillaries (rincaps $50 \mu \mathrm{L}$, ca. 1 mm inner diameter from Hirschmann, Germany) was adapted from the procedure we developed in Twardoch et al., ${ }^{45}$ using in that case acidic $\mathrm{pH}$ conditions for the $\mathrm{TiO}_{2}$ nanoparticle suspension, and detailed in SI2. Illumination of the capillaries was performed outside the EPR 
cavity with an UV neon-based lab-made illumination chamber. Each neon presents a $\lambda_{\max }=365$ $\mathrm{nm}(\mathrm{hv}=3.4 \mathrm{eV})$ and $\mathrm{E} \approx 1.5 \mathrm{~mW} \cdot \mathrm{cm}^{-2}$. The emission spectra of the neons and a schematic description of the experimental setup are presented in Supporting Information SI5.

\subsection{Gas-phase photocatalytic tests}

The photocatalytic activity and behavior of LbL films on model surfaces have been assessed by their ability to degrade and mineralize gaseous $\mathrm{HCOOH}$ under UV-A irradiation in a singlepass continuous gas flow reactor, with a flat configuration derived from that detailed in the ISO 22197 standard series (More details on the reactor and on the experimental setup can be found in Supporting Information SI6). ${ }^{46,47}$ The reactor was placed in a thermostated chamber for maintaining a constant temperature of $25^{\circ} \mathrm{C}$ during the test according to ISO standards, since heat generated by the lamp during the irradiation could not be neglected. The photocatalytic tests were performed at a gaseous $\mathrm{HCOOH}$ concentration of $45 \mathrm{ppm}_{\mathrm{v}}$, at a relative humidity of $50 \%$ (about $3 \%$ relative to the total atmospheric pressure), and with a total air flow rate of 20 $\mathrm{ml} / \mathrm{min}$, corresponding to a velocity of $0.74 \mathrm{~cm} / \mathrm{s}^{-1}$ and a residence time of $10.8 \mathrm{~s}$ in the reaction zone of the reactor.

The photocatalysts were first exposed to the inlet polluted air flow with no illumination until dark adsorption equilibrium was reached, before the UV-A illumination was switched on. The UV-A illumination was provided by a $8 \mathrm{~W}$ UV-A blacklight lamp (Sylvania Blacklight Blue F8W/BLB T5), with a spectral peak centered on $365 \mathrm{~nm}$, placed above the reactor $(1.5 \mathrm{~cm})$, parallel to the film. The film was exposed to an irradiance of $2.5 \mathrm{~mW} . \mathrm{cm}^{-2}$, recorded using a wideband spectroradiometer (RPS900-W ILT). The catalytic activity was evaluated under steady state conditions, typically achieved after $3 \mathrm{~h}$ of irradiation. No change in activity was observed for all samples for $24 \mathrm{~h}$ after reaching steady state conditions. 
The photocatalytic performances were obtained by on-line quantifying both inlet and outlet flows using a R3000A gas micro-chromatography (SRA instruments), equipped with thermal conductivity micro-detectors, allowing quantification of $\mathrm{HCOOH}$, water and $\mathrm{CO}_{2}$. All the photocatalytic tests have been performed twice, and the photocatalytic data corresponded to the averaged data, with a relative accuracy of $\pm 5 \%$.

The photocatalytic activity of the films was expressed in terms of both $\mathrm{HCOOH}$ conversion and $\mathrm{CO}_{2}$ formed, while the $\mathrm{CO}_{2}$ concentration was compared to the stoichiometric $\mathrm{CO}_{2}$ concentration, corresponding to $100 \%$ selectivity to $\mathrm{CO}_{2}$ of the $\mathrm{HCOOH}$ oxidation reaction (Eq. $2-3)$.

$\mathrm{HCOOH}$ conversion $(\%)=\frac{\left[\mathrm{HCOOH}_{\text {in }}\right]-\left[\mathrm{HCOOH}_{\text {out }}\right]}{\left[\mathrm{HCOOH}_{\text {in }}\right]} \times 100$

Theoretical $\mathrm{CO}_{2}\left(\mathrm{ppm}_{\mathrm{v}}\right)=\left[\mathrm{HCOOH}_{\mathrm{in}}\right]-\left[\mathrm{HCOOH}_{\text {out }}\right]$

The activity of the photocatalytic films was also expressed in terms of quantum yields, calculated for a wavelength range from 300 to $800 \mathrm{~nm}$. Quantum yields are based on a "number ratio", either of photoconverted molecules over absorbed photons or over photons entering the reactor. $^{48}$

The apparent quantum yield $\eta_{\mathrm{app}}$, takes into account the reaction rate and the rate (flux) of photons emitted by the UV-A lamp (and more precisely the rate of photons received by the film), while the efficient quantum yield (or quantum yield) $\eta$ takes into account the number of photons that have been absorbed by the films, as follows:

$$
\begin{aligned}
& \eta_{\text {app }}=\frac{r}{\phi_{\text {received }}} \\
& \eta=\frac{r}{\phi_{\text {absorbed }}}
\end{aligned}
$$

where $r$ is the reaction rate (in $\mathrm{mol}$ of $\mathrm{HCOOH} / \mathrm{min}$ ), $\phi_{\text {received }}$ is the rate of received photons and $\phi_{\text {absorbed }}$ is the rate of photons absorbed with : 


$$
\begin{aligned}
& \phi_{\text {received }}=\int_{\lambda_{\min }}^{\lambda_{\max }} \frac{P(\lambda)}{E(\lambda)} d(\lambda) \\
& \phi_{\text {absorbed }}=\int_{\lambda_{\min }}^{\lambda_{\max }} \frac{P(\lambda) \times\left(1-10^{-A(\lambda)}\right)}{E(\lambda)} d(\lambda)
\end{aligned}
$$

$P$ is the irradiation power at a given wavelength (in W) with $P(\lambda)=I(\lambda) \times 10^{-6} \times S$ with $I$ being the irradiance received by the film surface $\left(\mathrm{W} . \mathrm{cm}^{-2}\right)$ and $S$ the surface area of the film (36 $\left.\mathrm{cm}^{2}\right) . E$ is the photon energy (in $\mathrm{J}$ ) with $\mathrm{E}=\frac{\mathrm{hc}}{\lambda}$.

\subsection{Photocatalytic antibacterial activity of the substrates}

Experiments were conducted with a GFP-producing E. coli strain, E. coli $\mathrm{SCC} 1 . .^{49,50}-80^{\circ} \mathrm{C}$ frozen bacterial cells were spread on a LB (Lysogeny broth, Sigma-Aldrich) agar plate and cultured at $30^{\circ} \mathrm{C}$ for $48 \mathrm{~h}$. A first suspension was prepared with one colony in LB, incubated overnight at $30^{\circ} \mathrm{C}$ and used to prepare a second suspension (10\% vol. in fresh LB). After incubation for $4 \mathrm{~h}$ at $30^{\circ} \mathrm{C}$, bacteria were harvested by centrifugation and re-suspended in physiological serum $\left(\mathrm{NaCl}(9 \mathrm{~g} / \mathrm{L}, \mathrm{pH} 6.8)\right.$ adjusted to a $600 \mathrm{~nm}$ absorbance of $0.1\left(510^{7} \mathrm{CFU}\right.$ $\mathrm{mL}^{-1}$ ). The material substrates were placed in $35 \mathrm{~mm}$ Petri dishes and inoculated with $3 \mathrm{ml}$ of this suspension. After $3 \mathrm{~h}$ of incubation at $30^{\circ} \mathrm{C}$, they were washed three times with $2 \mathrm{ml}$ physiological serum without creating air-surface interface. Adhered bacteria were in situ observed (i.e., in the last washing solution) under a fluorescence confocal microscope (LSM700, Carl ZEISS) equipped with a X63 water immersion objective (W Plan Apochromat $\mathrm{X} 63 / 1.0,2.0 \mathrm{~mm}$ ) (excitation and acquisition wavelengths at $488 \mathrm{~nm}$ and $528 \mathrm{~nm}$ respectively). The substrates were exposed to UV-A irradiation $\left(3 \mathrm{~mW} / \mathrm{cm}^{2}\right)$ for $60 \mathrm{~min}$ and propidium iodide (PI, Aldrich-Sigma) dye was added to stain membrane-damaged bacteria. Again, adhered bacteria were in situ observed under the confocal microscope (excitation and acquisition 
wavelengths at $488 \mathrm{~nm}$ and $645 \mathrm{~nm}$ respectively). For biofilm assessment, the last washing solution was replaced by LB medium for $15 \mathrm{~h}$ of further growth at $30^{\circ} \mathrm{C}$. Then, washing was performed as previously described and PI was added in the last washing solution before in situ observation under confocal microscope. The quantity of bacteria was determined on the doublechannel RGB images using Image ${ }^{\circledR} 1.47 \mathrm{~V}$ software. Bacteria with active green GFP metabolism or damaged membrane as demonstrated by PI staining are called "Live" and "Damaged" in the following text, respectively. For each experiment, 7 locations were observed on each surface sample, and two identical substrates of each type were analyzed. Experiments were repeated three times. Results are expressed as average \pm standard deviation. Significance of differences was tested by Student $t$-test.

\section{RESULTS}

\section{1. $\mathrm{TiO}_{2}$ and polyelectrolyte film construction monitoring and characterization}

First, X-Ray Diffraction analysis showed that the procedure applied to the Aeroxide ${ }^{\circledR} \mathrm{TiO}_{2}$ P25 suspension with final centrifugation step removed some larger size $\mathrm{TiO}_{2}$ crystallites from the $\mathrm{TiO}_{2}$ suspension (Figure $\mathrm{S} 1 \mathrm{~A}$, Table 1). Indeed, the suspension used for $\mathrm{LbL}$ was found to be composed of $92 \mathrm{wt} . \%$ anatase with mean crystallite sizes of $17 \mathrm{~nm}$ for anatase, and $22 \mathrm{~nm}$ for rutile, while a slightly higher fraction of rutile phase was observed at $19 \%$ for the $\mathrm{P} 25 \mathrm{TiO}_{2}$ powder, with slightly higher mean crystallite sizes of 20 and $32 \mathrm{~nm}$, respectively, for anatase and rutile phases.

Considering analysis accuracy, the XRD patterns recorded for single layer pair and 10 layer pairs LbL films constructed on silicon wafers showed no preferential deposition of anatase or rutile phase (Figure S1B, Table 1). The rutile intensity peak was found to be almost in the signal 
threshold most likely due to the low titania content in the single layer pair film, and only the anatase phase with $18 \mathrm{~nm}$ in mean diameter size was observed. By contrast, the 10 layer pairs film was made of $94 \%$ anatase $(18 \mathrm{~nm})$ and $6 \%$ rutile $(22 \mathrm{~nm})$.

Dynamic Light Scattering (DLS) analyses revealed the presence of $\mathrm{TiO}_{2}$ crystallite aggregates with a mean diameter size of $91 \pm 1 \mathrm{~nm}$ (Figure S2), with no significant change over the time necessary for building the $\mathrm{TiO}_{2} /$ polyelectrolyte multilayer films. It is worth noting that the size homogeneity for both the individual titania crystallites and their aggregates is of importance for building homogeneous films though the layer-by-layer deposition method.

Table 1: Weight fraction and mean crystallite size of anatase and rutile phases in $\mathrm{TiO}_{2} \mathrm{P} 25$ as powder and from the LbL suspension, as well as in the $\mathrm{PEI} / \mathrm{PSS} / \mathrm{TiO}_{2}$ film with 1 and 10 layer pairs. $\left(^{*}\right)$ peak intensity is too low for accurate measurements.

\begin{tabular}{lllll}
\hline TiO & & \multicolumn{2}{c}{ Weight fraction $(\mathbf{w t . \%}){ }^{\mathbf{a}}$} & \multicolumn{2}{c}{ Crystallite size (nm) $^{\mathbf{b}}$} \\
& Anatase & Rutile & Anatase & Rutile \\
\hline $\mathrm{P} 25$ powder & 81 & 19 & 20 & 32 \\
$\mathrm{P} 25$ suspension for $\mathrm{LbL}$ & 92 & 8 & 17 & 22 \\
$\mathrm{PEI} / \mathrm{PSS} / \mathrm{TiO}_{2}$ & 100 & $(*)$ & 18 & $(*)$ \\
$\mathrm{PEI} /\left(\mathrm{PSS} / \mathrm{TiO}_{2}\right)_{10}$ & 94 & 6 & 18 & 22 \\
\hline
\end{tabular}

a The phase composition corresponds to the weight fraction within the crystallized $\mathrm{TiO}_{2}$ phases determined using the most intense peaks at $25.3^{\circ}$ and $27.1^{\circ}$ corresponding to the diffraction of the (101) and (110) planes of anatase (JCPDS card 21-1272) and rutile (JCPDS card 21-1276), respectively. $\mathrm{TiO}_{2}$ samples contain as well $7 \%$ of amorphous $\mathrm{TiO}_{2}$ as determined by using the method developed in ref ${ }^{51}$.

${ }^{\mathrm{b}}$ The mean $\mathrm{TiO}_{2}$ crystallite size, that is the average size of the coherently-diffracting domains, was determined from the Scherrer equation applied with the usual assumption of spherical crystallites to the (101) and (110) peaks of anatase and rutile, respectively. 
Build-up of the $\mathrm{PEI} /\left(\mathrm{PSS} / \mathrm{TiO}_{2}\right)_{\mathrm{n}}$ films on the silicon wafer substrate $\left(36 \mathrm{~cm}^{2}, 4.5 \times 8 \mathrm{~cm}\right)$ was conducted by an automated dipping robot. The colors observed at the surface of the samples, arising from optical interferences, showed that titania was homogeneously deposited on the substrate (Figure 1A). The Layer-by-Layer construction of the $\mathrm{TiO}_{2}$ and polyelectrolyte films was monitored through ellipsometry, SEM UV-visible spectrophotometry in transmission and QCM-D measurements. The ellipsometry characterization revealed the linear increase in the film thickness after the deposition of each $\mathrm{PSS} / \mathrm{TiO}_{2}$ layer pair, with an average apparent thickness increment of $40 \mathrm{~nm} \pm 5 \mathrm{~nm}$ per $\mathrm{PSS} / \mathrm{TiO}_{2}$ layer pairs as well as a good film thickness homogeneity materialized by the low standard deviations (Figure 1B, Table 2). While the average aggregate size was found to be centered at $91 \pm 1 \mathrm{~nm}$, the thickness of the titania layer was found to be lower than the DLS measurement, but higher than the mean crystallite size of the main phase, i.e. anatase, derived from XRD. This may indicate that the sample's surfaces are not fully homogeneously covered by $20 \mathrm{~nm}$ diameter anatase crystallites, but rather by small-size $\mathrm{TiO}_{2}$ aggregates, providing an average thickness of $40 \mathrm{~nm}$ for the layers, and creating a high porosity within the layered films films that directly results from the inter-crystallite space as well as from the space between the $\mathrm{TiO}_{2}$ aggregates. This might be more pronounced for the single layer pair film, for which the average thickness of the layer was higher than that calculated for the next (upper) layers. 

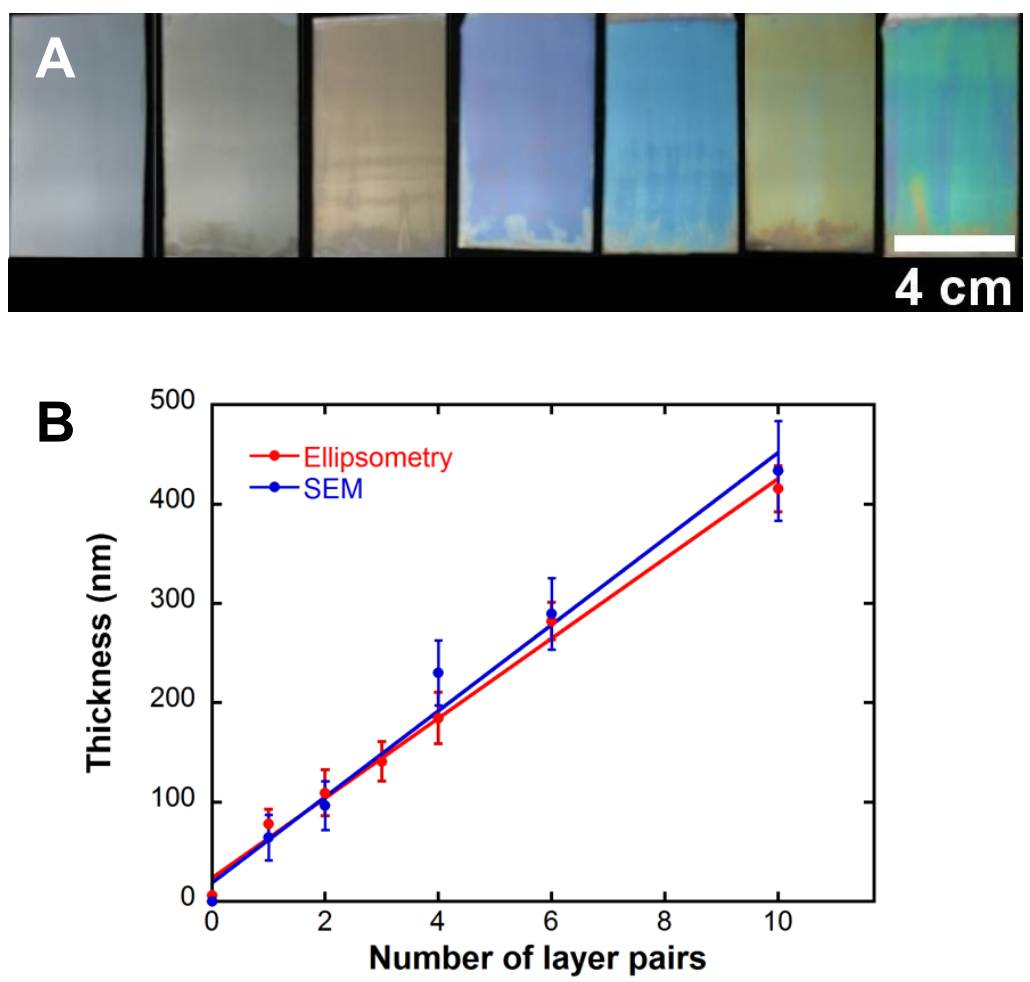

Figure 1: (A) Optical photographs of PEI/(PSS/TiO $)_{n}$ films built on silicon wafers. From left to right: bare silicon wafer, $\mathrm{PEI} / \mathrm{PSS}$ film, $\mathrm{PEI} / \mathrm{PSS} / \mathrm{TiO}_{2}, \mathrm{PEI} /\left(\mathrm{PSS} / \mathrm{TiO}_{2}\right)_{2}, \mathrm{PEI} /\left(\mathrm{PSS} / \mathrm{TiO}_{2}\right)_{4}$, $\mathrm{PEI} /\left(\mathrm{PSS} / \mathrm{TiO}_{2}\right)_{6}$ and $\mathrm{PEI} /\left(\mathrm{PSS} / \mathrm{TiO}_{2}\right)_{10}$. (B) Increase in thickness of PEI/(PSS/TiO $)_{\mathrm{n}} \mathrm{LbL}$ films obtained by ellipsometry and SEM as a function of the number of layer pairs. A linear increase in thickness is observed at the deposition conditions reported here. 


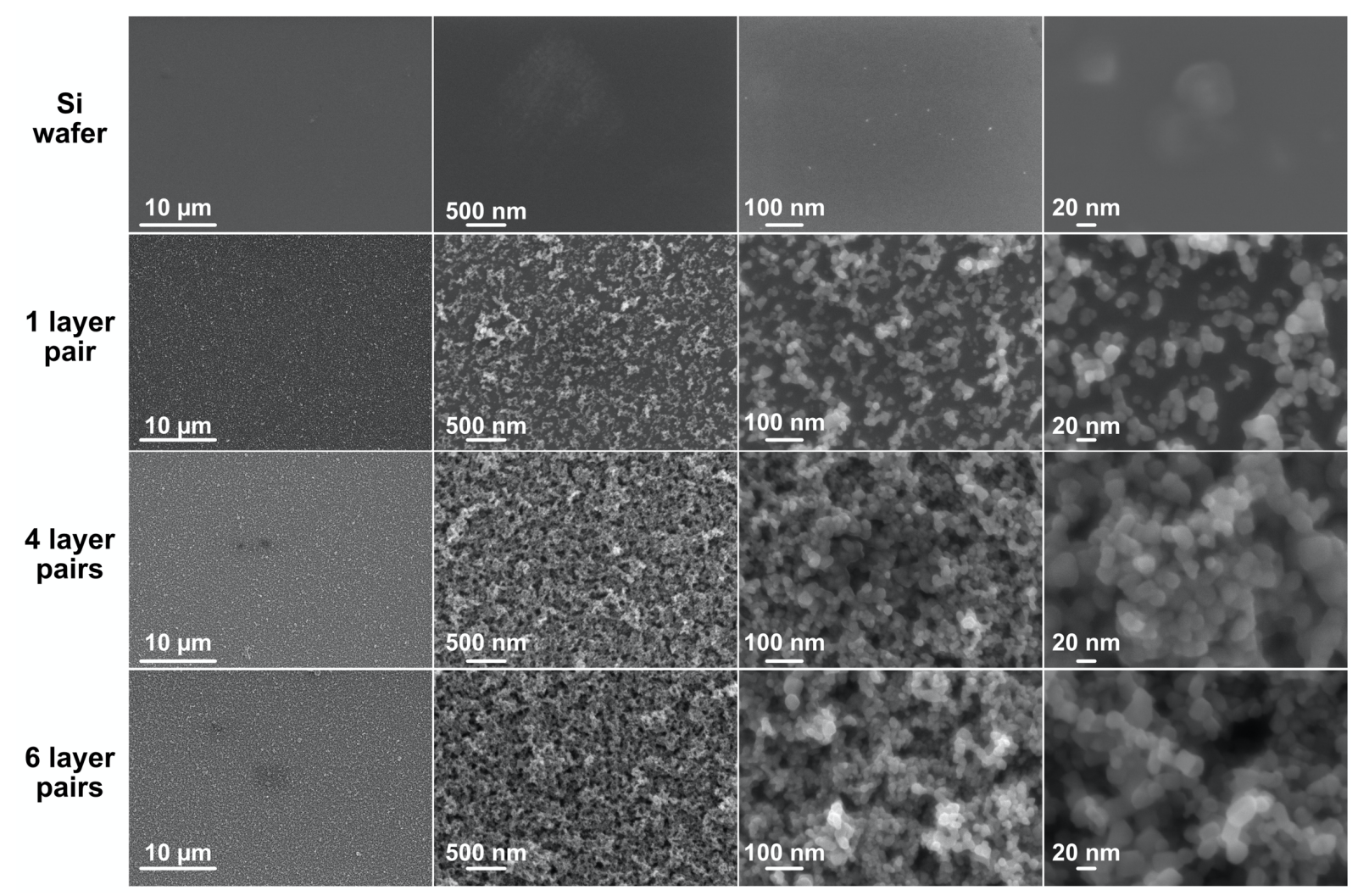

Figure 2: SEM images of titania and polyelectrolytes LbL films built on silicon wafers, with different numbers of $\mathrm{PSS} / \mathrm{TiO}_{2}$ layer pairs. It must be stressed that on the thicker films such as eg. the 6 layer pair film, the dark zones do not correspond to the naked substrate (ie. $\mathrm{TiO}_{2}$-free zones), but appears dark due to a thickness contrast effect (see further the cross-section images evidencing the complete substrate coverage when increasing the number of layer pairs).

The SEM images of the PEI/(PSS/TiO $)_{n}$ films showed the homogeneity of the films at the micrometer scale, whatever the number of layer pairs, while on the contrary they clearly revealed their heterogeneity at the nanometric scale, which provides to the films their porous structure, as visualized on both top-view and cross-section images (Figures 2 and 3). This porous structure was also observed on $\mathrm{PSS} / \mathrm{TiO}_{2} \mathrm{LbL}$ films on different substrates in the works of Rongé et al. ${ }^{33}$ and Dontsova et al. ${ }^{32}$ While a fairly good coverage of the silicon wafer by $\mathrm{TiO}_{2}$ nanoparticles was already observed for a single layer pair film, the cross sections images did 
not show any stratified structure with well-defined polyelectrolyte and titania layers, and the surface coverage became total and the films became denser with the increase in the number of layer pairs (Figure 3). An average thickness increase of $43 \mathrm{~nm}$ per layer pair was derived from the film cross section analysis, in agreement with the ellipsometry results (Table 2 and Figure 1B).

Table 2: Film thickness obtained by ellipsometry and SEM characterisations.

\begin{tabular}{lll}
\hline Sample & \multicolumn{1}{c}{ Ellipsometry $(\mathbf{n m})^{\mathbf{a}}$} & SEM cross section $(\mathbf{n m}){ }^{\mathbf{b}}$ \\
\hline $\mathrm{PEI} / \mathrm{PSS} / \mathrm{TiO}_{2}$ & $78 \pm 15$ & $65 \pm 23$ \\
$\mathrm{PEI} / \mathrm{PSS} /\left(\mathrm{TiO}_{2}\right)_{2}$ & $110 \pm 23$ & $97 \pm 25$ \\
$\mathrm{PEI} / \mathrm{PSS} /\left(\mathrm{TiO}_{2}\right)_{3}$ & $141 \pm 20$ & - \\
$\mathrm{PEI} / \mathrm{PSS} /\left(\mathrm{TiO}_{2}\right)_{4}$ & $185 \pm 27$ & $230 \pm 33$ \\
$\mathrm{PEI} / \mathrm{PSS} /\left(\mathrm{TiO}_{2}\right)_{6}$ & $282 \pm 19$ & $290 \pm 36$ \\
$\mathrm{PEI} / \mathrm{PSS} /\left(\mathrm{TiO}_{2}\right)_{10}$ & $416 \pm 23$ & $434 \pm 50$ \\
\hline
\end{tabular}

${ }^{a}$ Whatever the number of layer pairs of the films, no significant change in the thickness of the films was observed after the gas phase photocatalytic tests under UV-A.

${ }^{\mathrm{b}}$ We have to stress that the cross-sections may have slightly suffered from the heat produced by the ion beam. They however stay in good agreement with the values derived from ellipsometry. 

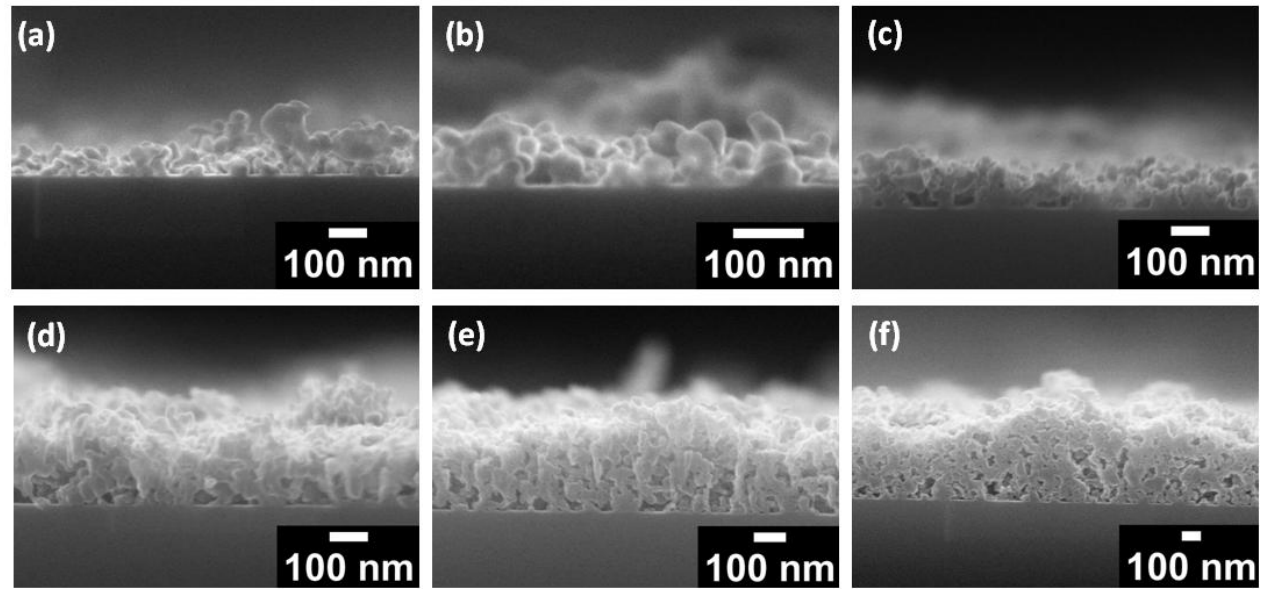

Figure 3: Cross section SEM images of $\mathrm{PEI} /\left(\mathrm{PSS} / \mathrm{TiO}_{2}\right)_{\mathrm{n}} \mathrm{LbL}$ films built on silicon wafers. $\mathrm{n}=1$ (a and b), n=2 (c), n=4 (d), n=6 (e) and n=10 (f). Brightness and contrast of SEM images were treated with Image $\mathrm{J}($.

The LbL film construction was also monitored though QCM-D experiments, that showed that no film deconstruction occurred while performing the alternate dipping and rinsing process (Figure 4 and Figure S3). Moreover, the difference in frequency changes while depositing materials has shown that the amount of PSS is increasing after every deposition step (Table S1), indicating that either more PSS is deposited after each deposition step, or more water molecules are adsorbed on the film. The superhydrophilicity of $\mathrm{PSS} / \mathrm{TiO}_{2} \mathrm{LbL}$ films after 2 layer pairs have been deposited, may have played a role, as proposed by Kommireddy et $a l .{ }^{52}$ High dissipation values highlight the adsorption of water on LbL films after each titania nanoparticle deposition, and suggests that $\mathrm{PSS} / \mathrm{TiO}_{2}$ does not act as a rigid film, but more like a viscous one, as confirmed by the absence of any curve overlap for the frequency changes at the different overtones analysed. 


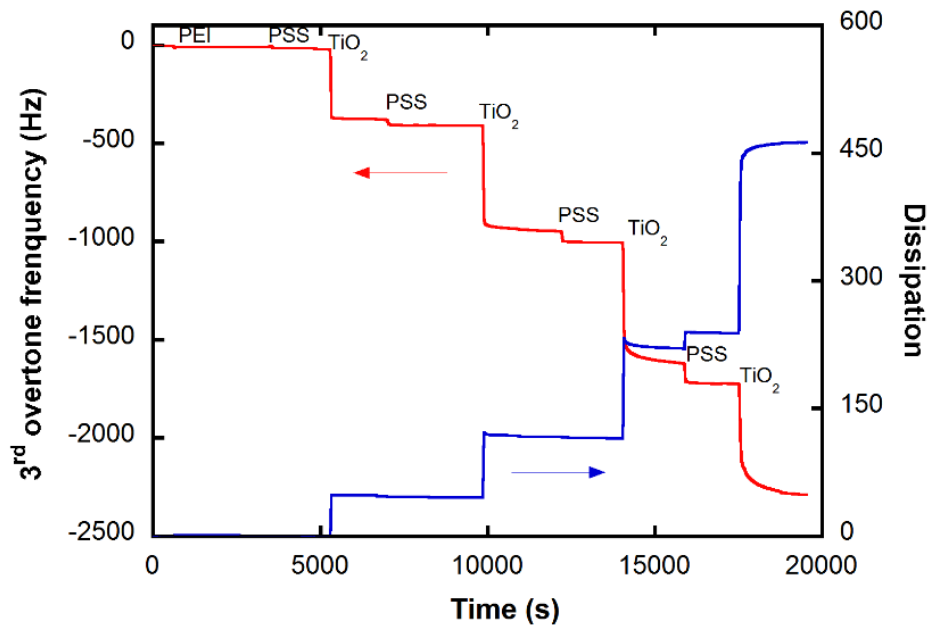

Figure 4 : Monitoring $\mathrm{PEI} /\left(\mathrm{PSS} / \mathrm{TiO}_{2}\right)_{\mathrm{n}}$ film construction by QCM-D at the $3^{\text {rd }}$ overtone. 4 $\mathrm{PSS} / \mathrm{TiO}_{2}$ layer pairs were deposited.

The above-mentioned characterizations were also implemented for estimating the amount of titania deposited per layer. QCM-D data at the $3^{\text {rd }}$ overtone $(n=3)$ indicated the deposition of $6.3 \mu \mathrm{g} / \mathrm{cm}^{2}$ of $\mathrm{TiO}_{2}$ within the first layer pair, while an average of $10.1 \pm 0.7 \mu \mathrm{g} / \mathrm{cm}^{2}$ of $\mathrm{TiO}_{2}$ deposited was estimated for the subsequent layers (ie. excluding the first layer pair). However, this value includes the amount of water adsorbed onto the film, which increased the mass of deposited material. Therefore, while the first layer deposited is reasonable to determine the amount of material deposited, the amount of materials deposited in the films for the next layers is overestimated ; indeed, the deposition of the next layers does not include the drying step using QCM and the exact modelling of dissipation and mass appeared too complex in such a system.

The film construction was also monitored on quartz slides through UV-visible spectrophotometry in transmission mode (Figure 5). A linear increase in absorbance in the UV region was observed while depositing $\mathrm{TiO}_{2}$ layers on the substrate surface, indicating that the 
multilayer building process increased regularly the amount of $\mathrm{TiO}_{2}$ within the film. More precisely, absorbance and transmittance values at $300 \mathrm{~nm}$ in wavelength were recorded, in regards to the number of layer pairs deposited. This wavelength was suitable since PSS absorbs at $225 \mathrm{~nm}$, which therefore does not affect absorbance results at $300 \mathrm{~nm} \cdot{ }^{30}$ Results showed a linear increase of 0.28 in absorbance per layer pair, while an exponential decay profile was reported for the transmittance at $300 \mathrm{~nm}$ with increasing the number of layer pairs. Hence, a film composed of six layer pairs displayed a low residual transmittance of $2 \%$.

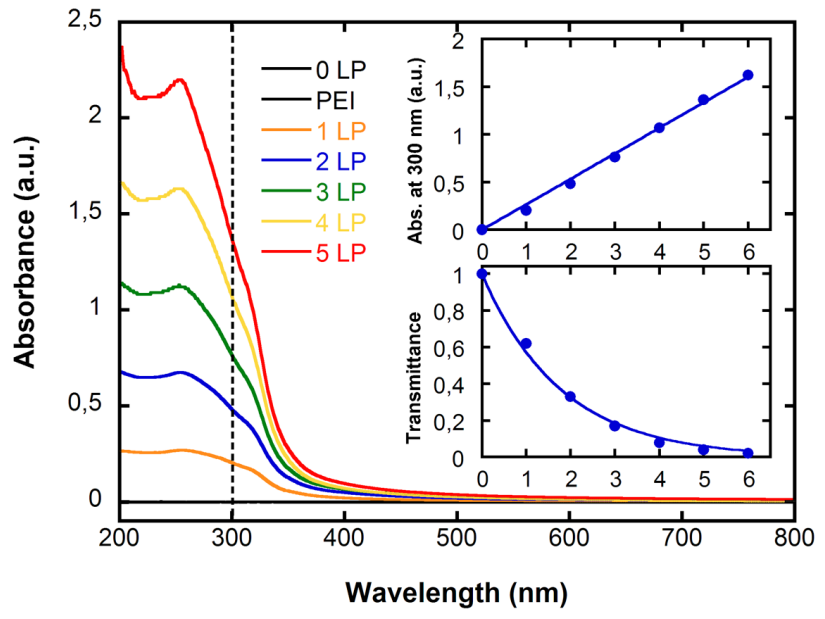

Figure 5: UV-Visible spectrophotometry characterisation in transmission mode of the $\mathrm{PEI} /\left(\mathrm{PSS} / \mathrm{TiO}_{2}\right)_{\mathrm{n}}$ films built on quartz slide, with absorbance increment after each layer pair deposited. (Insets) absorbance and transmittance at $300 \mathrm{~nm}$ in regards to the number of layer pairs deposited.

By neglecting the light scattering and assuming identical extinction values of $\mathrm{TiO}_{2}$ in aqueous suspension and in the LbL titania films built on quartz slide, UV-Vis spectrophotometry in transmission mode can be considered as a valuable time-saving and cheap method for 
approximating the titania amount increment per layer pair. From Supporting Information SI2, it has been estimated at $4.7 \pm 0.5 \mu \mathrm{g} / \mathrm{cm}^{2}$.

By contrast to both QCM-D and UV-vis spectrophotometry measurements, the ICP-AES chemical analysis operates without assumptions and neglected parameters, for providing accurately the amount of titanium within the films. It evidenced a linear increase in the amount of titania deposited on silicon wafer with a density of $7.0 \pm 0.7 \mu \mathrm{g} / \mathrm{cm}^{2}$ per layer deposited (Figure S4), and the values derived from ICP-AES measurements were used further in the study. The fill factor $f$ of the film was consequently estimated at 0.44 (Supporting Information SI3). In comparison to that of about 0.74 observed for hexagonally close-packed hard spheres, this corroborates the porous structure of the film.

Each physical measurement is limited in accuracy by the specific sample in a specific experiment and by the models applied for deriving the data, so that it is not surprising that some methods slightly differ with respect to the determination of a specific quantity. The key-aspect is that all data fall into the same ballpark, which they do in our case, and that the obtained data allows the monitoring of the multilayer films's construction.

\subsection{Photocatalytic activity}

Figure 6A-D depicts the influence of the number of layer pairs on the performances of the $\mathrm{PEI} /\left(\mathrm{PSS} / \mathrm{TiO}_{2}\right)_{\mathrm{n}}$ films in the degradation of the $\mathrm{HCOOH}$ pollutant, expressed in terms of $\mathrm{HCOOH}$ conversion, number of $\mathrm{HCOOH}$ molecules degraded per unit of time and of catalyst mass, apparent quantum yield $\eta_{\mathrm{app}}$, quantum yield $\eta$ and concentration of $\mathrm{CO}_{2}$ formed, the values being summarized in Table 3. It shows that the $\mathrm{HCOOH}$ conversion profile followed an unusual behaviour with the increase in the number of layer pairs, ie. with the increase in the amount of titania within the film (Figure 6A). Indeed, for such low thickness films, ie. films in the 50-500 nm thickness sub-micronic range with low $\mathrm{TiO}_{2}$ content, the conversion was 
expected to be proportional to the amount of photocatalyst. ${ }^{53,54}$ By contrast, a high $\mathrm{HCOOH}$ conversion of $94 \%$ was observed for a single layer pair film, with a decrease of conversion rate for films containing a second and third layer of titania, respectively $63 \%$ and $60 \%$. For a higher number of layer pairs, the photocatalytic conversion increased to $72 \%$ and subsequently reached a plateau after 6 layer pairs in the film, with a conversion rate of $86-88 \%$.

After normalization to the amount of $\mathrm{TiO}_{2}$ photocatalyst in the film, Figure 6B depicts as well the unusual behaviour of the film composed of a single layer pair, for which the highest number of $\mathrm{HCOOH}$ molecules degraded per unit of time and of catalyst mass (ie. in $\mathrm{mol} / \mu \mathrm{g} / \mathrm{min}$ ) was achieved. As soon as a second layer pair was built, this number first drastically dropped down, before it further slightly decreased with increasing the number of layer pairs, evidencing that most of the $\mathrm{HCOOH}$ degradation is done here by the upper layers.
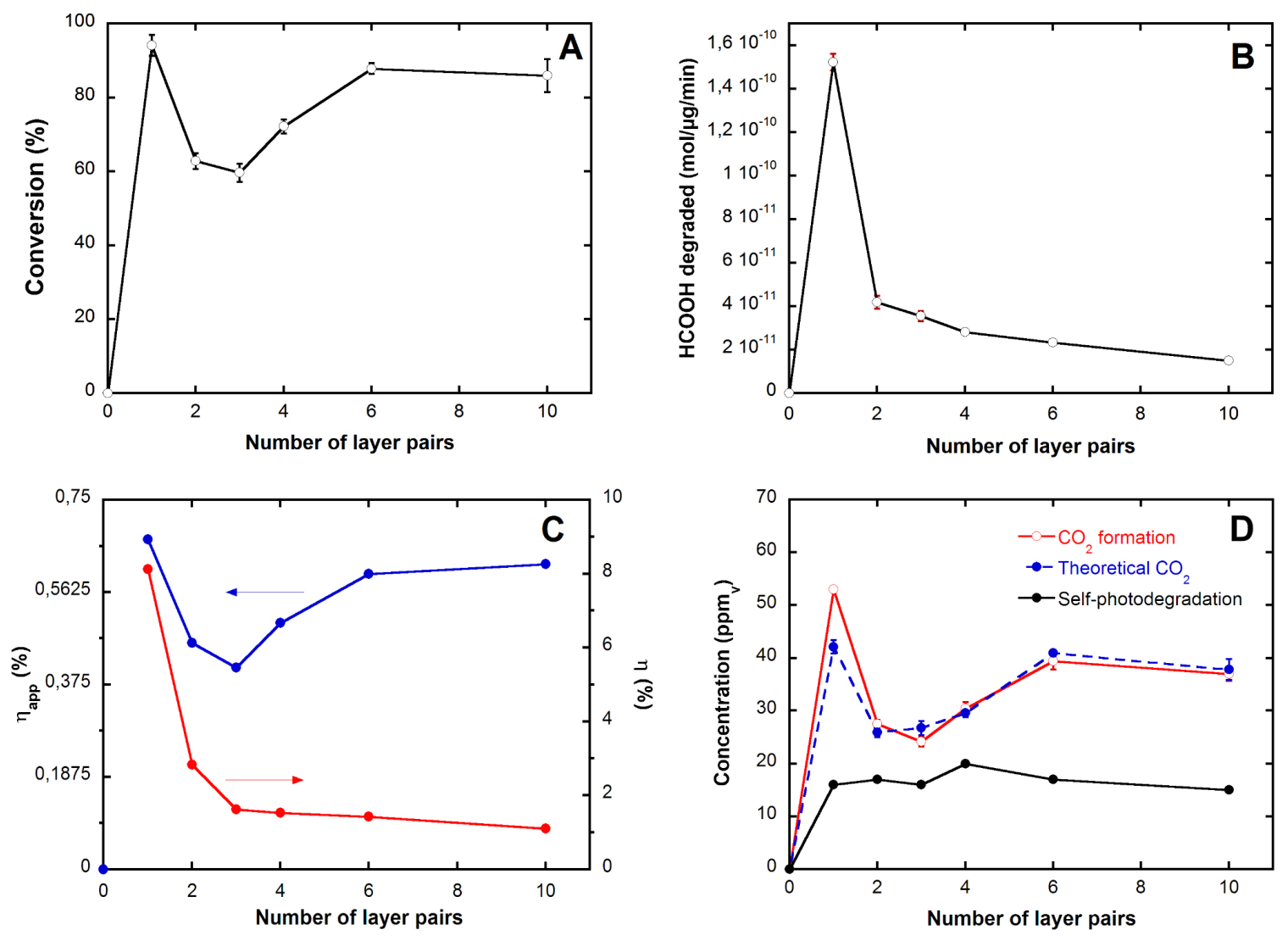
Figure 6: Influence of the number of layer pairs on (A) the HCOOH conversion, (B) the number of $\mathrm{HCOOH}$ molecules degraded in mol per $\mu \mathrm{g}$ of $\mathrm{TiO}_{2}$ per minutes, (C) both apparent quantum yield $\eta_{\text {app }}$ and quantum yield $\eta$, and (D) the $\mathrm{CO}_{2}$ concentration, obtained with the LbL $\mathrm{PEI} /\left(\mathrm{PSS} / \mathrm{TiO}_{2}\right)_{\mathrm{n}}$ films. Experimental parameters: $[\mathrm{HCOOH}]=45 \mathrm{ppm}_{\mathrm{v}}$, air flow $=20 \mathrm{~mL} / \mathrm{min}$, speed $=0.7 \mathrm{~cm} / \mathrm{s}$, UV-A irradiance $=2.5 \mathrm{~mW} \cdot \mathrm{cm}^{-2}$, films built on $36 \mathrm{~cm}^{2}$ silicon wafers. On the graph (D), the concentration of $\mathrm{CO}_{2}$ stoichiometrically formed from the converted $\mathrm{HCOOH}$ is reported for comparison, as well as the $\mathrm{CO}_{2}$ concentration formed upon UV-A irradiation of the films in the absence of any inlet $\mathrm{HCOOH}$ flow (total humid air flow of $20 \mathrm{~mL} / \mathrm{min}$ ).

The $\mathrm{CO}_{2}$ formation curve followed the same trend than that of the $\mathrm{HCOOH}$ conversion, with a maximum $\mathrm{CO}_{2}$ concentration formed of $53 \mathrm{ppm}_{\mathrm{v}}$ for a single pair of layer film (Figure 6D and Table 3). The $\mathrm{CO}_{2}$ concentration decreased once adding a second and a third $\mathrm{PSS} / \mathrm{TiO}_{2}$ layer pair, to 28 and $24 \mathrm{ppm}_{\mathrm{v}}$, respectively, before subsequently increasing and reaching a plateau at about $38 \mathrm{ppm}_{\mathrm{v}}$ after 6 layer pairs films. As observed for the $\mathrm{HCOOH}$ conversion results, the $\mathrm{CO}_{2}$ value obtained for a single layer pair film overcomes those obtained on films with a higher number of layer pairs. In comparison to the amount of $\mathrm{CO}_{2}$ stoichiometrically formed from the converted $\mathrm{HCOOH}$, an overproduction of $11 \mathrm{ppm}_{\mathrm{v}}$ was observed for the $\mathrm{PEI} / \mathrm{PSS} / \mathrm{TiO}_{2} \mathrm{LbL}$ film. Therefore, upon irradiation, a single layer pair film $\mathrm{PEI} / \mathrm{PSS} / \mathrm{TiO}_{2}$ may not only degrade gas phase formic acid, but may also degrade polyelectrolytes contained within the film. However, this overproduction was suppressed once a second layer pair was constructed, so that the LbL titania film is degrading mainly $\mathrm{HCOOH}$ and not the polyelectrolytes, and the $\mathrm{CO}_{2}$ concentration formed corresponds to the stoichiometric concentration formed by the oxidation of $\mathrm{HCOOH}$.

Further, independently of the number of layer pairs within the film, submitting the film to the same flow rate and light conditions but in the absence of any inlet $\mathrm{HCOOH}$ pollutant led to the 
formation of a small amount of $\mathrm{CO}_{2}\left(\mathrm{ca} .16 \mathrm{ppm}_{\mathrm{v}}\right)$, close to the $\mathrm{CO}_{2}$ overproduction obtained on the $\mathrm{PEI} / \mathrm{PSS} / \mathrm{TiO}_{2}$ single layer pair film during the photocatalytic oxidation of $\mathrm{HCOOH}$. The results suggest that the photocatalytic self-degradation of the $\mathrm{PEI} /\left(\mathrm{PSS} / \mathrm{TiO}_{2}\right)_{\mathrm{n}} \mathrm{LbL}$ films upon UV-A irradiation is concerned more with the degradation of the PEI polyelectrolyte rather than with that of PSS, since the $\mathrm{CO}_{2}$ formation remains independent of the number of $\mathrm{PSS} / \mathrm{TiO}_{2}$ layer pairs within the film. This did not impact on the stability of the performances, as no reduction of the photocatalytic efficiency of the films was observed when the test duration was extended over more than $24 \mathrm{~h}$, as expressed in the section 2.5 . In consequence, reusability tests performed on some of the films by introducing a darkness period of $12 \mathrm{~h}$ between two tests under illumination did not reveal any change neither in the $\mathrm{HCOOH}$ conversion nor in the $\mathrm{CO}_{2}$ formation.

The photocatalytic activity of the films was also expressed in terms of apparent and efficient quantum yields (Figure 6C). We know that the number of photons entering the reactor is a parameter much simpler to measure. The apparent quantum yield being related to the reaction rate and to the photons received by the titania film, and not to the absorption of the film, the results show a similar trend to the $\mathrm{HCOOH}$ conversion curve with a maximum apparent quantum yield for a single layer pair film $(0.67 \%)$, followed by a decrease in yield until 3 layer pairs film $(0.41 \%)$. The apparent quantum yield then increases again up to a plateau level at about $0.6 \%$ for a film composed of $6-10$ layer pairs.

As far as the quantum yield assessment was concerned by considering the light absorption profile of the films, although the reflective surfaces can lead to measurement approximation due to light back-scattering or forward-scattering from the catalyst particles, ${ }^{55}$ a maximum quantum yield of $8.1 \%$ was obtained for a single layer film, which is 6-7 times higher than the quantum yields achieved with 6-10 LP films, at ca. 1.1-1.4\%. 
Table 3. $\mathrm{HCOOH}$ conversion, number of $\mathrm{HCOOH}$ molecules degraded per unit of time and of catalyst mass, apparent quantum yield $\eta_{\mathrm{app}}$, quantum yield $\eta$, concentration of $\mathrm{CO}_{2}$ formed and theoretical concentration of $\mathrm{CO}_{2}$ formation, as a function of the number of layer pairs and of the TiO content in the $\mathrm{PEI} /\left(\mathrm{PSS} / \mathrm{TiO}_{2}\right)_{\mathrm{n}}$ films.

\begin{tabular}{|c|c|c|c|c|c|c|c|}
\hline Multilayer films & $\begin{array}{l}\text { Amount of } \\
\mathrm{TiO}_{2} \text { deposited } \\
\left(\mu \mathrm{g} / \mathrm{cm}^{2}\right)^{\mathrm{a}}\end{array}$ & $\begin{array}{l}\text { HCOOH } \\
\text { conversion } \\
(\%)\end{array}$ & $\begin{array}{l}\mathrm{HCOOH} \text { molecules } \\
\text { degraded }\left({\mathrm{x} 10^{-11}}\right. \\
\mathrm{mol} \mathrm{HCOOH} / \mu \mathrm{g} \\
\left.\mathrm{TiO}_{2} / \mathrm{min}\right)\end{array}$ & $\begin{array}{l}\text { Apparent } \\
\text { quantum yield, } \\
\eta_{\text {app }}(\%)\end{array}$ & $\begin{array}{l}\text { Quantum } \\
\text { yield, } \eta \\
(\%)\end{array}$ & $\begin{array}{l}\mathrm{CO}_{2} \\
\text { formation } \\
\left(\mathbf{p p m}_{\mathrm{v}}\right)\end{array}$ & $\begin{array}{l}\text { Theoretical } \\
\mathrm{CO}_{2} \text { formation } \\
\left(\mathrm{ppm}_{\mathrm{v}}\right)\end{array}$ \\
\hline $\mathrm{PEI} / \mathrm{PSS}$ & 0 & 0 & 0 & 0 & 0 & 0 & 0 \\
\hline $\mathrm{PEI} / \mathrm{PSS} / \mathrm{TiO}_{2}$ & $7 \pm 0.7$ & $94 \pm 3$ & $15.2 \pm 0.3$ & 0.67 & 8.13 & $53 \pm 1$ & $42 \pm 1$ \\
\hline $\mathrm{PEI} /\left(\mathrm{PSS} / \mathrm{TiO}_{2}\right)_{3}$ & $17 \pm 0.1$ & $60 \pm 2$ & $3.5 \pm 0.1$ & 0.41 & 1.62 & $24 \pm 1$ & $27 \pm 1$ \\
\hline $\mathrm{PEI} /\left(\mathrm{PSS} / \mathrm{TiO}_{2}\right)_{4}$ & $24 \pm 0.1$ & $72 \pm 2$ & $2.8 \pm 0.1$ & 0.50 & 1.53 & $30 \pm 1$ & $30 \pm 1$ \\
\hline $\mathrm{PEI} /\left(\mathrm{PSS} / \mathrm{TiO}_{2}\right)_{6}$ & $41 \pm 0.2$ & $88 \pm 1$ & $2.3 \pm 0.1$ & 0.60 & 1.43 & $39 \pm 2$ & $41 \pm 1$ \\
\hline
\end{tabular}

${ }^{a}$ Values derived from ICP-AES measurements 


\subsection{TRMC and EPR characterization of multilayer films}

Information on the number of excess charge carriers created by the TRMC pulse $\left(\mathrm{I}_{\max }\right)$ was provided, as well as indications on life-time of charge carriers which may undergo recombination or trapping $\left(\mathrm{I}_{40} / \mathrm{I}_{\max }\right)$. TRMC experiments on $\mathrm{TiO}_{2}$ based semi-conductors are often realized directly on powders, which does not necessarily reflect how the materials will behave in film. In the present case, TRMC signals have been determined directly on the multilayer films, placed at the extremity of the microwave guide.

Figure 7 depicts the time-evolution of the TRMC signal at the nanoscale recorded for the $\mathrm{PEI} /\left(\mathrm{PSS} / \mathrm{TiO}_{2}\right)_{\mathrm{n}}$ films as well as the influence of the number of layer pairs on both $\mathrm{I}_{\max }$ and $\mathrm{I}_{40} / \mathrm{I}_{\max }$ parameters. No TRMC signal was observed on the bare glass slide and the PEI/PSS film used as control samples. While the $I_{\max }$ evolution profile showed that the number of photogenerated charge carriers increases according to the number of layer pairs built, i.e. with increasing the amount of $\mathrm{TiO}_{2}$ in the film, the most useful information was related to the absence of any significant TRMC signal for the single layer pair film, from which no $I_{\max }$ and $\mathrm{I}_{40}$ values could consequently be extracted. This directly resulted from the low amount of titania, and allowed us to rule out the hypothesis of the generation of an especially-high number of charge carriers in respect to the amount of $\mathrm{TiO}_{2}$ contained in the single layer pair film. Further, no significant influence of the number of $\mathrm{TiO}_{2}$ layers on the $\mathrm{I}_{40} / \mathrm{I}_{\max }$ ratio was observed, indicating that the charge carrier lifetimes within the titania LbL films were not depending on the number of layer pairs. It must be said that no plateau was observed for the number of charge carriers created upon laser irradiation with increasing the number of layer pairs, due to the high photon density (order of magnitude equal to $10^{23}$ photons $\cdot \mathrm{s}^{-1} \cdot \mathrm{cm}^{-2}$ ) in comparison to that received by the films during the photocatalytic tests 
performed with a $2.5 \mathrm{~mW} \cdot \mathrm{cm}^{-2}$ irradiance (i.e. corresponding to an order of magnitude equivalent to $10^{15}$ photon $\cdot \mathrm{s}^{-1} \cdot \mathrm{cm}^{-2}$ ).
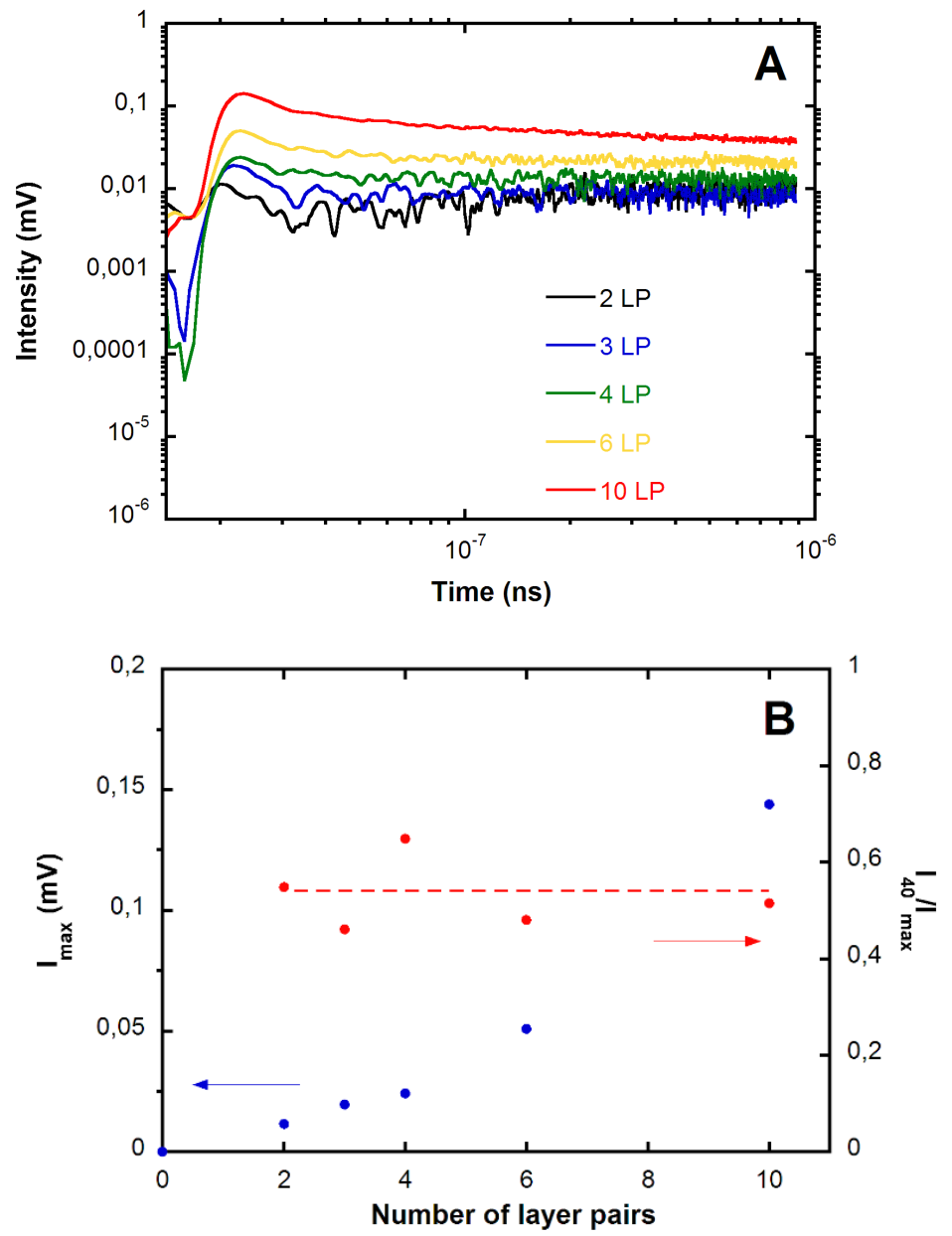

Figure 7: (A) TRMC signal obtained upon UV-A irradiation of the $\mathrm{PEI} /\left(\mathrm{PSS} / \mathrm{TiO}_{2}\right)_{\mathrm{n}}$ films built on glass slides. (B) Influence of the number of layer pairs of the LbL films on both $I_{\max }$ and $I_{40} / I_{\max }$ parameters. No significant signal could be observed for a single layer pair film, mainly due to the low amount of titania in the film, resulting in the signals being lost in TRMC threshold. 
EPR characterization was performed for providing information on the electron photogeneration in the $\mathrm{PEI} /\left(\mathrm{PSS} / \mathrm{TiO}_{2}\right)_{\mathrm{n}}$ films by monitoring the TEMPOL decay signal (spin-scavenging) in regards of the UV-A illumination time. ${ }^{45}$. Indeed, being a stable radical, TEMPOL is reduced while reacting with photo-mediated reactive species. ${ }^{56}$ Therefore TEMPOL decay kinetics can be directly related to the amount of accessible photogenerated electrons at the surface of $\mathrm{TiO}_{2}$ in the film under UV-A. It must be stressed that, in contrary to the TRMC measurements, the excitation source is comparable to that used in the photocatalytic tests, i.e. neon-type with an irradiance equal to $1.5 \mathrm{~mW} \cdot \mathrm{cm}^{-2}$ (which corresponds to an order of magnitude equal to $10^{15}$ photon s$^{-1} \mathrm{~cm}^{-2}$ ). EPR investigation of the $\mathrm{PEI} /\left(\mathrm{PSS} / \mathrm{TiO}_{2}\right)_{\mathrm{n}} \mathrm{LbL}$ films revealed an expected trend for such films regarding the decay of the TEMPOL EPR signal, that gets faster as the number of titania layers built in the capillaries increases (Figure 8A and $k$ data in Figure 8B). By normalizing the initial rate of TEMPOL reduction by the number of deposition steps ( $k / n$ data, Figure $8 \mathrm{~B})$, the average kinetic per layer pair is probed. If we first put aside the $k$ and $k / n$ values obtained for a single layer pair film, the decay rate $k$ was proportional to the number of layer pairs, which is also expressed by almost constant $k / n$ values independently of the number of layer pairs for $n \geq 3$. This evidences that the amount of photogenerated species linearly increases with increasing the number of layer pairs for $\mathrm{n} \geq 3$, and is consequently directly proportional to the amount of $\mathrm{TiO}_{2}$ contained in the $\mathrm{LbL}$ film. This indicated that no light screening phenomena was observed within the films for irradiances of an order of magnitude similar to those used in the photocatalytic tests.

By contrast, it is worth noting that the single layer pair film displayed clearly a faster decay rate of the TEMPOL EPR signal than the LbL films with 3-10 layer pairs, as the normalized $k / n$ kinetics stands out of those obtained for such films (Figure 8B). This has to be put into perspective with the higher photocatalytic activity of the single layer pair film in comparison to that of thicker films. 

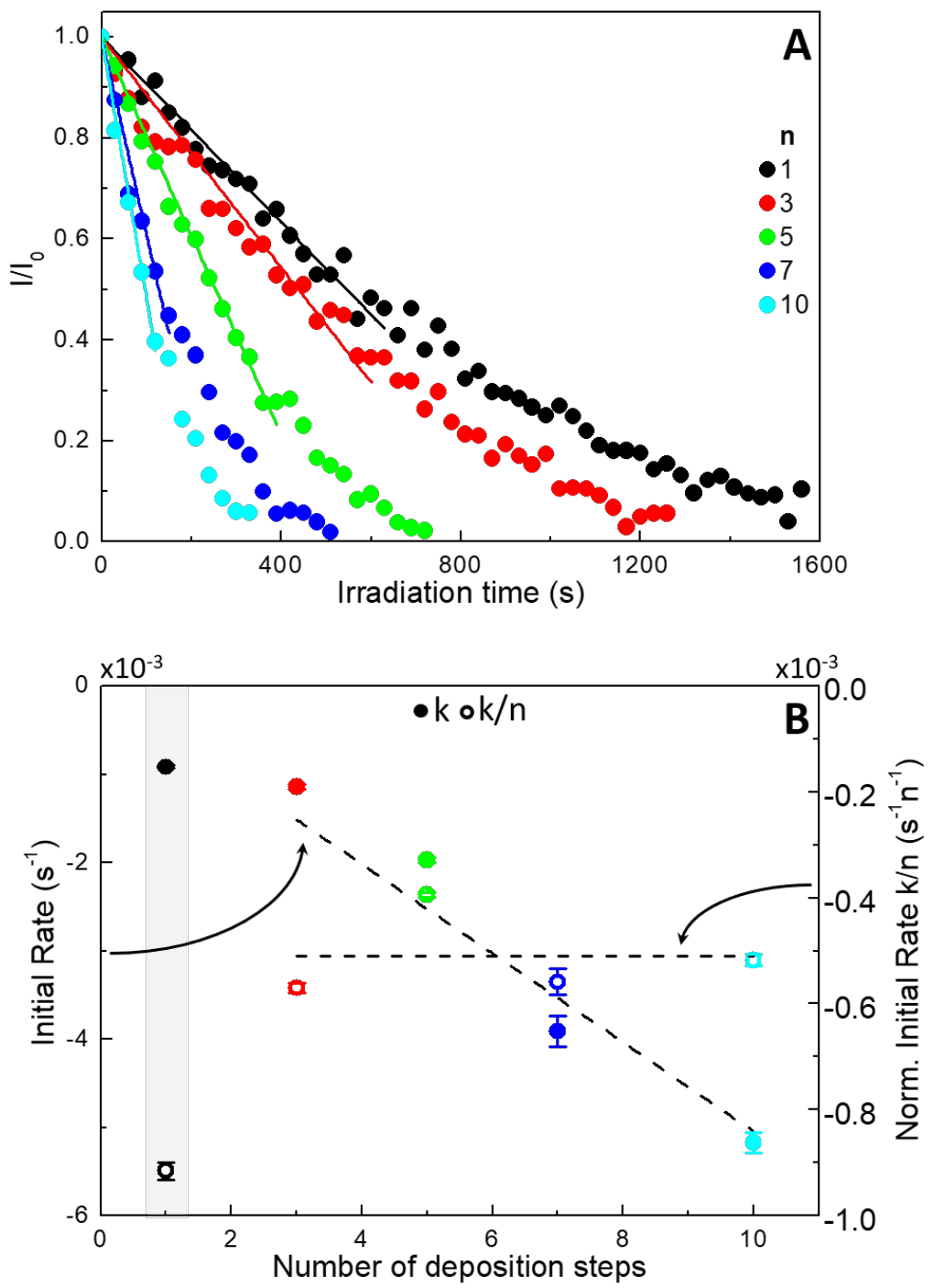

Figure 8: (A) Evolution of the normalized TEMPOL EPR intensity $\left(\mathrm{I} / \mathrm{I}_{0}\right)$ as function of illumination time for the $\mathrm{PEI} /\left(\mathrm{PSS} / \mathrm{TiO}_{2}\right)_{\mathrm{n}}$ films with $\mathrm{n}=1,3,5,7,10, n$ being the number of deposition steps (i.e. the number of layer pairs built). (B) Evolution as a function of $n$ of the initial rate $k$ (filled circles) derived from the linear fit of the $\mathrm{I} / \mathrm{I}_{0}$ curve (straight lines in main graph) and of the corresponding $k / n$ values normalized with the number of deposition steps. The grey area highlights the peculiar behavior obtained for a single layer pair film. 


\subsection{Photocatalytic antibacterial activity}

The films were not sterilized prior to activity assessment for preventing them from any possible degradation of the polyelectrolytes. Unintended contamination by some microorganisms was prevented by maintaining the films in sterile milli-Q baths from their production under clean condition to their use. In addition, the titania multilayer films were shown to be stable under immersion in a $\mathrm{NaCl}$ aqueous solution $(9 \mathrm{~g} / \mathrm{l})$ for $15 \mathrm{~h}$. Indeed, ellipsometry did not reveal any decrease in film thickness, demonstrating that the films were stable in the conditions used for the bacteria assays (Table S2). On the contrary, a small increase in thickness $(14 \pm 7 \mathrm{~nm})$ was observed, which was associated to a slight swelling of the LbL films, known to find its origin in the need of the "waterborne species" to establish an equilibrium between the solid-like film and the adjacent liquid or humidity, by regulating differences in the chemical potential or the osmotic pressure. ${ }^{12}$

The number of active ("Live") and damaged bacteria ("Damaged") was assessed before and after UV-A irradiation on a series of control (i.e. without $\mathrm{TiO}_{2}$ ) and $\mathrm{TiO}_{2}$-containing $\mathrm{LbL}$ films. Knowing ionic strength of the culture medium $(\mathrm{Is}=0.15 \mathrm{M})$, their potential difference in surface charge especially due to the presence of $\mathrm{TiO}_{2}$ (measured IEP at $6.1 \pm 0.2$ ) is not expected to have influenced the surface colonization by bacteria (IEP $<7^{57,58}$ ). No significant decrease in bacteria number was observed when submitting the series of control substrate (silicon wafer) and films (PEI, PEI/PSS, PEI/PSS/PDDA, PEI/PSS/PDDA/PSS) to UV-A light for $60 \mathrm{~min}$. Therefore, bactericidal properties of the silicon wafer substrate and of the immobilized polyelectrolytes under UV-A irradiation could be ruled out (Figure S5). An increase in bacteria number was even observed on these surfaces except on the silicon wafer and PEI film surfaces, whilst low numbers of damaged bacteria were counted after irradiation. This is the result of both the bacterial growth 
during the irradiation time and the low, harmless irradiance $\left(3 \mathrm{~mW} . \mathrm{cm}^{-2}\right)$ received by bacteria on the films.

Although PEI is known for its antibacterial properties ${ }^{24,59}$ the absence of any antibacterial activity for the surface coated only with a PEI layer - and a fortiori when the initial PEI layer is masked by additional polyelectrolyte layers -, may result from the loss in mobility of PEI chains when PEI strongly adhered to the substrate as ultra-thin layer (average thickness estimated at 11.5 $\AA$, in Felix et al. ${ }^{60}$ This is prone to prevent immobilized PEI to intimately interact with the bacterial cell wall to significantly degrade it, as required according to the mechanism of the bactericidal action of PEI, and to make re-dissolution of PEI impossible over the time-scale of months, preventing PEI action in solution Further, only very low amount of PEI is deposited on the substrate, estimated at $119 \mathrm{ng} / \mathrm{cm}^{2}$ from QCM-D measurements using the $3^{\text {rd }}$ overtone.

However, "live" bacteria number on PEI surface after UV-A irradiation did not increase as much as on the other control films. Direct contact of bacteria with the PEI layer may have indeed weakened the bacterial membranes, thus resulting in an inhibition of the bacterial growth in combination with the toxic effect of irradiation. On the bare silicon wafer also, the bacterial growth expected in $60 \mathrm{~min}$ is inhibited under UV-A irradiation. This slight effect of $60 \mathrm{~min}$ UV-A irradiation on a control surface free of photocatalyst differs from Yan's results that did not report any effect of a similar irradiation time (45 $\mathrm{min}$ ) on a glass surface. ${ }^{49}$ However, the high reflectivity of silicon wafer (refractive index of 6.5 at $365 \mathrm{~nm}$ ) may have cause more diffusion of light and therefore more exposition to UV-A of bacteria on silicon wafer compared to the other substrates, leading to higher toxicity of irradiation on this surface. Both minor effects were not observed on other control surfaces when additional polyelectrolyte layers were deposited on the PEI-coated substrate. 


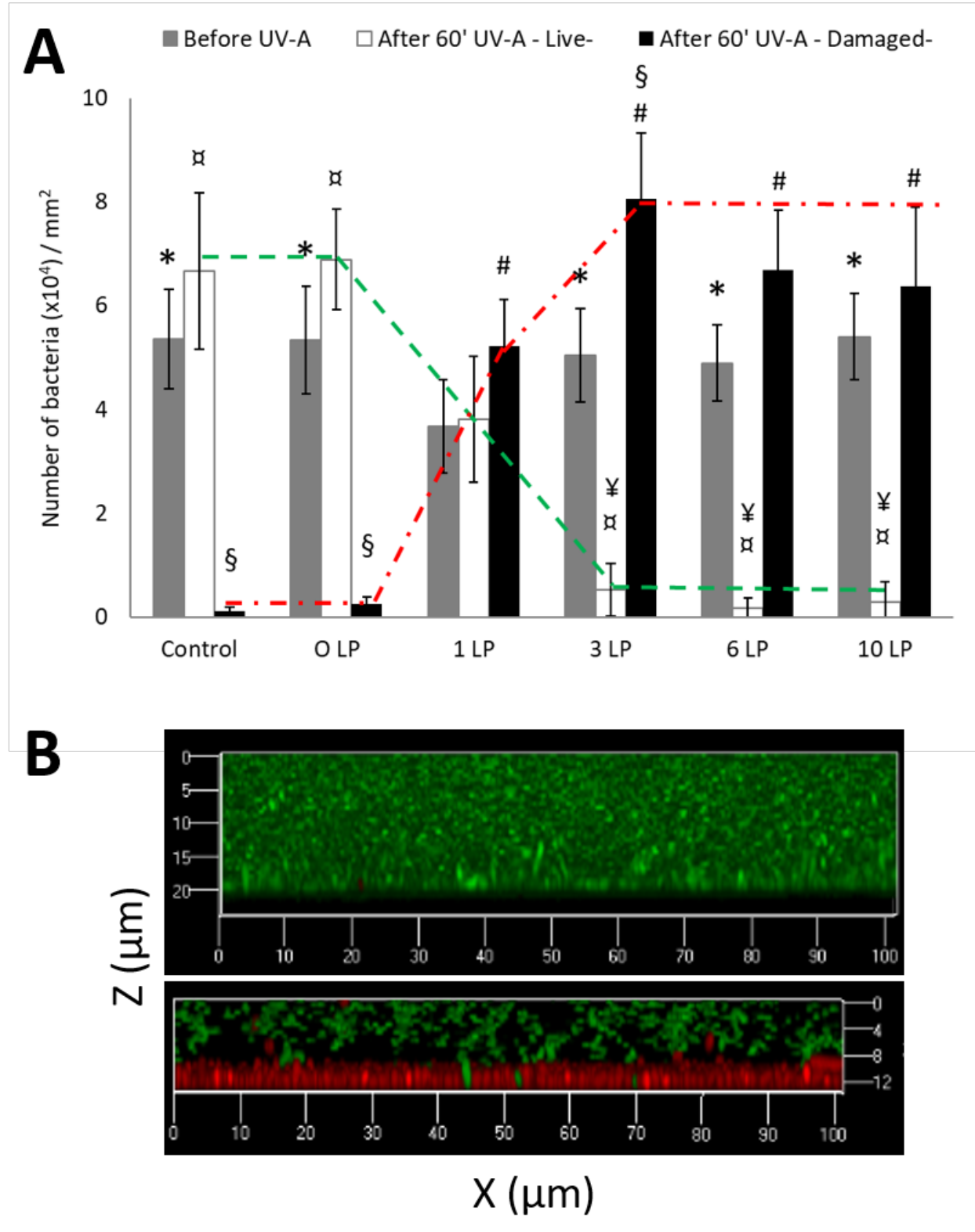

Figure 9: (A) Number of adhered E. coli bacteria on the control ((PEI/PSS)/(PDDA/PSS) 9 ) and the $\mathrm{TiO}_{2}$-containing films $\left(\mathrm{PEI} /\left(\mathrm{PSS} / \mathrm{TiO}_{2}\right)_{\mathrm{n}}\right.$ with $\mathrm{n}$ from 0 to 10 ), before (total population of bacteria) and after 60 min UV-A irradiation ("live" and "damaged" bacteria) (irradiance of 3 $\left.\mathrm{mW} . \mathrm{cm}^{-2}\right)$. Films were built on $2 \mathrm{~cm}^{2}$ silicon wafers. Trends are depicted by green and red dashed 
lines. *: significant difference to 1 LP before UV-A ( $p$-value $<0.05)$; $(\propto)$ significant difference in live quantity compared to $1 \mathrm{LP}$ after UV-A ( $p$-value $<0.05$ ); (¥) significant difference in live quantity compared to $0 \mathrm{LP}, 1 \mathrm{LP}$ and the control after UV-A ( $p$-value $<0.05$ ); (\#) significant difference in damaged quantity compared to 0 LP after UV-A ( $p$-value $<0.05)$; (§) significant difference in damaged quantity compared to 1 LP after UV-A ( $p$-value $<0.05)$. (B) Cross section of biofilms visualized under confocal microscope without (top) or after (bottom) UV-A treatment and further $15 \mathrm{~h}$ of growth in a rich and favorable medium.

The antibacterial activity of the photocatalytic $\mathrm{PEI} /\left(\mathrm{PSS} / \mathrm{TiO}_{2}\right)_{\mathrm{n}} \mathrm{LbL}$ films under UV-A irradiation was investigated for a number of $\mathrm{PSS} / \mathrm{TiO}_{2}$ layer pairs (n) varying from 0 to 10 deposited on a first PEI layer on silicon wafer (Figure 9A). The results were compared to those obtained on a control LBL film of the highest thickness i.e., with 10 layer pairs, expected to be inactive under UV-A irradiation due to the absence of $\mathrm{TiO}_{2}$. The PEI/(PSS/TiO $)_{2} \mathrm{LbL}$ films exhibited photocatalytic antibacterial properties upon UV-A irradiation once one single layer pair was deposited. Half of the bacteria observed on the film surface was active ("live") whilst the other half of the population was damaged ("damaged"). Increasing the number of layer pairs from 1 to 3 caused a clear further decrease in the number of active bacteria ("ALIVE") after irradiation with a simultaneous increase in the number of damaged bacteria ("damaged"), i.e. from $58 \%$ to $94 \%$. Further, almost all the bacteria observed on the films were damaged after UV-A irradiation for all the films composed of more than 3 layer pairs. Bacterial cells were not completely destroyed as shown by the total population of bacteria, i.e. the sum of active and damaged bacteria, but bacteria inactivation and cell wall degradation were almost complete (from $94 \%$ to $98 \%$ ) from 3 layer pairs. 
The complete inactivation of bacteria adhered on $\mathrm{TiO}_{2}$-containing coatings without complete lysis of cells is in agreement with the results reported by Yan et al. ${ }^{49}$ for similar irradiation times. Only much longer times of photocatalytic treatment $(75 \mathrm{~h})$ were described to provide complete mineralization of bacterial cells adhered on $\mathrm{TiO}_{2}$-containing surfaces, due to the high quantity of organic molecules that forms bacteria that should be degraded to completely destroy cells, as noted by other authors. ${ }^{61,62}$ It must be noted that the reusability of the coatings depends on the cleanliness of the surface, namely the quantity of bacterial debris issued from damaged bacteria remaining on the film after use. Those debris can be eliminated by extending the photocatalytic treatment time until bacteria are completely degraded, before the newly adhered bacteria could be treated.

As a result of the high rate of bacteria inactivation, it is worth noting that the formation of biofilm after further growth in a rich and favorable medium was significantly prevented and the resulting biofilm was affected by the photocatalytic treatment as illustrated in Figure $9 \mathrm{~B}$. About $20 \%$ of the whole biofilm thickness ( $13 \pm 5 \mu \mathrm{m}$ versus $12 \pm 4 \mu \mathrm{m}$ after irradiation) was significantly replaced by a dense layer of damaged bacteria $(0 \pm 0 \mu \mathrm{m}$ versus $2.6 \pm 0.7 \mu \mathrm{m}$ after irradiation $)$ and about $50 \%$ of the analyzed sample locations revealed biofilms with sparse rather than dense active cells. In addition, a layer $(2 \pm 1 \mu \mathrm{m})$ revealed the absence of visible active or damaged bacteria after irradiation at the bottom of the biofilm, whilst active bacteria were seen in contact with the material in the absence of treatment. This revealed the longer-term (biofilm-preventive) inactivation capacity of the photocatalytic $\mathrm{TiO}_{2}$ films, in addition to their immediate curative photocatalytic feature.

\section{DISCUSSION}




\subsection{Influence of the layer pair number on the multilayer films behaviour regarding formic acid mineralization}

The efficiency of the films in the degradation of gaseous pollutants is considered to result from several basic features, namely (i) the $\mathrm{TiO}_{2}$ amount in the film, here expressed in $\mu \mathrm{g} . \mathrm{cm}^{-2}$, (ii) the absorption of light by $\mathrm{TiO}_{2}$ in the film, and consequently the creation of electron and hole photogenerated charges, (iii) their availability at the $\mathrm{TiO}_{2}$ surface, that results from their transfer properties to the surface and the recombination ratio, (iv) the diffusion of the gaseous reactants within the film, and their subsequent adsorption at the surface of the irradiated $\mathrm{TiO}_{2}$ crystallites and (v) the intrinsic surface reactivity of the $\mathrm{TiO}_{2}$ photocatalyst.

With increasing the number of deposition steps, the construction of the films was characterized by a regular increase in the average film thickness, and was accompanied by a $\mathrm{TiO}_{2}$ amount increment per PSS/TiO 2 layer pair deposited being independent of the layer number. The film was consequently expected to follow a usual behaviour when increasing the $\mathrm{TiO}_{2}$ amount in the film, with a linear increase until the conversion reaches a plateau due to a screening of excess particles, which mask part of the particles due to the limited penetration thickness of UV-A light. ${ }^{54,55}$

Several characterization techniques were implemented on the multilayer films for assessing this light screening effect (UV-Visible spectrophotometry, EPR and TRMC measurements), for which the results might appear as contradictory at first glance. Indeed, spectrophotometry that is using a low number of incident photons (ca. $10^{11}$ photon $\mathrm{s}^{-1} \mathrm{~cm}^{-2}$ ) compared to the photocatalytic test, revealed a low residual light transmission of ca. $2 \%$ for more than 6 layer pairs - that might indicate a light screening effect, i.e. fewer photons reaching the $\mathrm{TiO}_{2}$ particles in the layers closer to the substrate. In contrast, this effect was not observed in EPR and TRMC measurements, that both confirmed that coatings with larger numbers of layer pairs produce more charges. 
This apparent mismatch finds directly its origin in the irradiance level to which the films are exposed during the different characterizations, and that consequently determines the number of photons that the first exposed layer pair is receiving, and in consequence also the number of photons that the deepest $\mathrm{TiO}_{2}$ layers are receiving. Independently of the number of incident photons, when the films are submitted to a high number of photons $\left(c a .10^{23}\right.$ photon s-1 $\mathrm{cm}^{-2}$ and $10^{15}$ photon $\mathrm{s}^{-1} \mathrm{~cm}^{-2}$ in the case of TRMC and EPR characterization, respectively, the number of photons in EPR being similar to that used during the photocatalytic test, the results suggested in both cases that films with larger numbers of layer pairs - and in consequence with higher $\mathrm{TiO}_{2}$ contents - produce more photogenerated charges. The number of the incident photons was high enough for allowing the deeper layers to still absorbed photons, and in consequence to generate charges. In that case, the PEI/(PSS/TiO $)_{n}$ films with nanometric thickness were not thick enough to suffer from any light screening effect. ${ }^{63}$ So, one can expect that the light absorption, i.e. the number of photons absorbed by each $\mathrm{TiO}_{2}$ layer, is in first approximation independent of the number and the location of the layer. This apparent discrepancy pointed out the necessity to apply the appropriate characterization technique in terms of light irradiance for drawing conclusions.

It must be noted that although films were built on silicon wafers, the possible reflection of the incident light by partially-covered areas of the substrate, cannot explain the high photocatalytic activity observed for the single layer film compared to that expected (extrapolated). Indeed, the number of $\mathrm{HCOOH}$ molecules that can be degraded could be doubled at the great maximum, while there is a factor of about 6 between both activities. In addition, the wafer coverage by a native surface oxide layer probably prevents from any charge transfer to the adjacent layer of $\mathrm{TiO}_{2}$.

Upon UV-A light absorption, the TRMC measurements indicates that charge carriers' life time was not influenced by the number of layers in the film, so that each $\mathrm{TiO}_{2}$ layer was considered as 
equivalent in terms of availability of the charges at the $\mathrm{TiO}_{2}$ crystallite surface. In consequence, other reasons should be put forward for explaining the very high $\mathrm{HCOOH}$ conversion achieved on the single layer pair film with ultra-low $\mathrm{TiO}_{2}$ content, as well as for understanding the conversion plateau observed for 6-10 layer pairs films, while no light screening was observed.

Regarding the $\mathrm{HCOOH}$ adsorption, no significant difference in terms of $\mathrm{HCOOH}$ uptake was observed in the dark between the different LbL-films before switching on the light. The first step of the $\mathrm{HCOOH}$ degradation, namely the adsorption at the $\mathrm{TiO}_{2}$ surface, is reported to occur molecularly as well as dissociatively, forming unsymmetrical and bidentate formates..$^{64,65,66}$ Further, Liao et al. demonstrated that molecularly-adsorbed $\mathrm{HCOOH}$ has a much higher photooxidation rate than its dissociatively-adsorbed counterpart, as formate, and they estimated this superiority at roughly 53 times ( $\pm 15 \%$ relative error) for a same surface concentration. ${ }^{64}$ The highest rate through the direct oxidation of molecular $\mathrm{HCOOH}$ can be put in perspective of the two-active-sites model developed by Muggli and Backes, that computed activities differing by a factor of at least $20 .{ }^{37}$ The conversion obtained with the films is thus mainly driven by the reactivity of the molecularly-adsorbed $\mathrm{HCOOH}$ reactant, since the dissociated formate is subjected to far lower photooxidation rates. Besides, regardless of the mechanism and the associated adsorption step, Liao et al. showed that the presence of co-adsorbed $\mathrm{H}_{2} \mathrm{O}$ enhanced the oxidation rates by almost a factor 2 .

If the activity obtained for a single layer pair is put aside, the increase in $\mathrm{HCOOH}$ conversion and in apparent quantum yield with increasing the number of layer pair clearly relates with the increase in the amount of irradiated $\mathrm{TiO}_{2}$ crystallites in the film. The plateau of performance obtained for films built with more than 6 layer pairs was proposed to result from diffusional limitation effects within the layered $\mathrm{PEI} /\left(\mathrm{PSS} / \mathrm{TiO}_{2}\right)_{\mathrm{n}}$ film. 
Indeed, keeping in mind that the photocatalytic activity of $\mathrm{TiO}_{2}$-polymer films was reported to be influenced by the conformation of the polyelectrolytes - polyelectrolytes with extended structures enabling lower photocatalytic activity than in the case of fuzzy structures by impacting on the diffusion of organic molecules ${ }^{67}$-, we proposed that the diffusion of the $\mathrm{HCOOH}$ reactant and of the water molecules within the film might be unfavoured in too thick (dense) layered films containing charged polyelectrolytes. The hindering of the transport of $\mathrm{HCOOH}$ and water molecules, their co-adsorption being known to be strongly beneficial to the $\mathrm{HCOOH}$ conversion, would favour an efficient use of the $\mathrm{TiO}_{2}$ upper layers. Unfortunately the transport properties of such molecules in multilayer films do not follow simple rules and the observed phenomena depend on the chemical nature of the polyelectrolytes and the chemical nature of the molecule, although the pores of the multilayer films are large enough to accommodate them. ${ }^{68}$ The increase in the film density with the increase in the number of layer pairs was observed by SEM. This can also be put into perspective with Rongé et al., who correlated a decrease in the apparent kinetic rate constant for methylene blue degradation when increasing the layer pair deposition time, to the construction of denser $\mathrm{TiO}_{2} /$ polyelectrolyte films. ${ }^{33}$ Upon the addition of layers, the film structure was reported to be self-organized and to become more compact, with a reduction of the film's porosity.

In addition, even though we cannot rule out that the diffusion of negatively-charged formate species in the film might be favoured in comparison to that of $\mathrm{HCOOH}$, due to the existence of electrostatic interaction and local electric fields between/within the charged layers, the conversion of formate species adsorbed in the deepest layers would suffer from a very low oxidation rate, and thus would not contribute significantly to the conversion obtained on the films.

Taking those hypotheses into consideration, the high conversion and quantum yields obtained for the single layer pair film might be explained by the full availability of the titania crystallites 
towards both $\mathrm{HCOOH}$ and water molecules. This higher accessibility was also effective in the case of the TEMPOL probe molecule, and is in agreement with the highest normalized $k / n$ kinetic decay rate of EPR signal in comparison to that obtained for thicker multilayer films. Consequently, the single layer pair film can take full advantage of the high photo-oxidation rate of molecularlyadsorbed $\mathrm{HCOOH}$ in the presence of co-adsorbed water molecules.

\subsection{Photocatalytic behaviour of multilayer films with specific architectures}

Specific architectures were built for testing the proposed explanation, and their efficiency was compared to that achieved on the $\mathrm{PEI} /\left(\mathrm{PSS} / \mathrm{TiO}_{2}\right)$ reference film with one single layer pair (Table S3). First, building (PSS/PDDA) 8 layers on the top of the first $\mathrm{PSS} / \mathrm{TiO}_{2}$ layer pair led to drastic drop of the conversion from $94 \%$ to $19 \%$, indicating that the (PSS/PDDA) 8 polyelectrolyte addlayers (with a $20 \mathrm{~nm}$ average thickness determined by ellipsometry) are acting as a diffusion barrier for the reactants in the films. Thus, the conversion was strongly lowered compared to the reference film free of any polyelectrolyte add-layer. The low conversion of $32 \%$ and $27 \%$ obtained on the $\mathrm{PEI} / \mathrm{PSS} / \mathrm{TiO}_{2} /(\mathrm{PSS} / \mathrm{PDDA})_{8} / \mathrm{PSS} / \mathrm{TiO}_{2}$ and the $\mathrm{PEI} /(\mathrm{PSS} / \mathrm{PDDA})_{8} / \mathrm{PSS} / \mathrm{TiO}_{2}$ films, respectively, confirmed that the availability of the $\mathrm{PSS} / \mathrm{TiO}_{2}$ layer against the reactant remained the key-feature of the films driving the $\mathrm{HCOOH}$ conversion. Indeed, a direct experimental evidence for the vertical diffusion and exchange processes of polyanions and polycations in polyelectrolyte multilayer films was reported by Lavalle et al. with the possibility for the polyelectrolyte to diffuse "in" and "out"

of the entire film during each bilayer deposition,${ }^{69}$ in agreement with theoretical works. ${ }^{70}$ Further, Kolasinska et al. showed that charged iron oxide nanoparticles deposited on PDDA/PSS multilayer films were subjected to diffusion inside the polyelectrolyte multilayer film and were incorporated consequently into the polyelectrolyte multilayer as an interfacial "mixture" of polyelectrolyte and 
nanoparticles, rather than to form a $2 \mathrm{D}$ layer on the top of it. ${ }^{71}$ By analogy, the building of a $\mathrm{PSS} / \mathrm{TiO}_{2}$ layer pair on the top of (PSS/PDDA) 8 layers might similarly lead to the diffusion and the (partial) incorporation of the $\mathrm{TiO}_{2}$ nanoparticles inside the polyelectrolyte layer pairs rather than to the formation of an add-layer on the underlying (PSS/PDDA) 8 layers. This is consistent with the lower conversions of $32 \%$ and $27 \%$ obtained with PEI $/ \mathrm{PSS} / \mathrm{TiO}_{2} /(\mathrm{PSS} / \mathrm{PDDA})_{8} / \mathrm{PSS} / \mathrm{TiO}_{2}$ and $\mathrm{PEI} /(\mathrm{PSS} / \mathrm{PDDA})_{8} / \mathrm{PSS} / \mathrm{TiO}_{2}$ films, respectively, for which the polyelectrolyte layers were acting as diffusion barrier for the reactant and were lowering the availability of the incorporated $\mathrm{TiO}_{2}$ nanoparticles. Those films, however, outperformed the PEI/PSS/TiO $/(\mathrm{PSS} / \mathrm{PDDA})_{8}$ film, since the $\mathrm{TiO}_{2}$ nanoparticles incorporated within the (PSS/PDDA) 8 multilayers remained probably more available for the reactant than when the (PSS/PDDA) 8 multilayers are directly built on the top of the $\mathrm{PEI} /\left(\mathrm{PSS} / \mathrm{TiO}_{2}\right)$ reference film with one single layer pair.

\subsection{Antibacterial behaviour of the multilayer films vs. $\mathrm{HCOOH}$ mineralization}

The increase in the antibacterial efficacy by increasing the number of layer pairs from $1(58 \%)$ to $3(94 \%)$ suggests that $\mathrm{TiO}_{2}$ nanoparticles not only from the top layer pair but also from deeper layer pairs are responsible for the antibacterial activity. However, given the constant efficacy of films with from 3 to 10 layer pairs, we proposed that only the three first top layer pairs contribute to the antibacterial activity. This probably results from the impossibility for bacteria to have contact points with layers located deeper than the three first top layer pairs due to a film porosity that not matches with the micron size of bacteria. Although it is obvious that the level of photocatalytic activity of the films on a small molecule such as $\mathrm{HCOOH}$ and on a complex assemblage of many macromolecules such as bacterial cells should not be expected to be similar, some characteristics of the films may have especially impacted their interface to the systems to be degraded, and therefore impacted some specific performances. 
Hence, the observed difference in the film behaviour against $\mathrm{HCOOH}$ and E. coli bacteria with increasing the number of layer pairs resulted

(i) from the film's surface heterogeneity at the nanometer scale, that probably enables bacteria to have contact points with $\mathrm{TiO}_{2}$ nanoparticles located not only in the top layer but also in the underlying layers. It has been reported that increase in the number of contact points, which can be obtained via the tuning of the surface topography of the films, promotes the antibacterial efficiency of $\mathrm{TiO}_{2}$ coatings. ${ }^{49}$

(ii) as well as from the porosity of the film that is in accordance with the size of a single molecule but not with the micron size of the $E$. coli bacteria, thus preventing them to diffuse within the film structure.

As a result, we proposed that the film structure allows the number of active contact points with bacteria to be increased by enabling the three first top layer pairs - but no supplementary layer pairs - to contribute to the antibacterial activity, as a result from the impossibility for bacteria to have contact points with layers located deeper due to a film porosity that not matches with the micron size of bacteria.

\section{CONCLUSION}

Virtually transparent $\mathrm{TiO}_{2} /$ polyelectrolyte thin multilayer films were built on model surfaces using electrostatic layer-by-layer assembly. Under UV-A irradiation such films showed excellent photocatalytic behavior for the removal of gaseous pollutant, taking $\mathrm{HCOOH}$ as model compound with high applicative interest, and as antibacterial surfaces, taking E.coli as model bacteria. Layer- 
by-Layer assembled $\mathrm{PEI}\left(\mathrm{PSS} / \mathrm{TiO}_{2}\right)_{\mathrm{n}}$ nano-composite coatings were prepared by immersion of different substrates in solutions containing negatively-charged NaPSS and positively-charged $\mathrm{TiO}_{2}$ nanoparticles. The gas-phase catalytic study revealed a peculiar dependence of the photocatalytic behavior of the $\mathrm{PEI} /\left(\mathrm{PSS} / \mathrm{TiO}_{2}\right)_{\mathrm{n}}$ films as a function of the number of layer pairs, deviating strongly from the activity profile usually reported in photocatalysis. Although no light screening was evidenced, a performance plateau was observed upon an increase in the number of layer pairs ( $>66)$, and was preliminarily attributed as to result from diffusion phenomena within the films that originate from the interaction of $\mathrm{HCOOH}$ and water with the nanoparticle/polyelectrolyte network. Most notably, a single layer pair film with a low $\mathrm{TiO}_{2}$ content of $7 \mu \mathrm{g} . \mathrm{cm}^{-2}$ outperformed films with a higher number of layer pairs, with a high quantum yield of $8.1 \%$ being 6-7 times higher than that of thicker films with higher amounts of $\mathrm{TiO}_{2}$. The optimum accessibility of the $\mathrm{TiO}_{2}$ crystallites in the first layer pair toward both $\mathrm{HCOOH}$ and water is considered to cause this unusual enhancement. In addition, we demonstrated that the three top layer pairs were contributing to the antibacterial photocatalytic activity of the $\mathrm{PEI} /\left(\mathrm{PSS} / \mathrm{TiO}_{2}\right)_{\mathrm{n}}$ films, due to the micron size of the $E$. coli bacteria as well as to the film surface heterogeneity, that allows the number of active contact points to be increased.

\section{ASSOCIATED CONTENT}

SI1 Substrate preparation

SI2 Quartz Crystal Microbalance with Dissipation monitoring (QCM-D) measurement

SI3 UV-Visible spectrophotometry in transmission mode

SI4 Time Resolved Microwave Conductivity (TRMC)

SI5 EPR characterization of multilayer films 
SI6 Schematic single-pass photocatalytic reactor used for the gas phase photocatalytic tests

Figure S1 XRD characterization of Aeroxide $\mathrm{TiO}_{2} \mathrm{P} 25$ suspensions and of multilayer films

Figure S2 DLS characterization of the Aeroxide $\mathrm{TiO}_{2}$ P25 suspension used for the LbL film construction

Figure S3 QCM-D measurements

Figure S4 ICP-AES chemical analysis of the multilayer films

Figure S5 Stability of films during the test protocols used for bacterial assays and control sample results

Table S1 Amount of deposited materials on LbL film calculated with QCM-D data from the $3^{\text {rd }}$ overtone.

Table S2 Evolution of the multilayer film thickness after being immerged in a $9 \mathrm{~g} / \mathrm{l} \mathrm{NaCl}$ solution, obtained by ellipsometry.

Table S3 HCOOH conversion obtained on specific architectures of films in comparison to that achieved on the $\mathrm{PEI} /\left(\mathrm{PSS} / \mathrm{TiO}_{2}\right)$ reference film with one single layer pair.

\section{AUTHOR INFORMATION}

\section{Corresponding Author}

*nkeller@unistra.fr

\section{Author Contributions}

The manuscript was written through contributions of all authors. All authors have given approval to the final version of the manuscript. Marvin Motay elaborated all films synthesized and carried out most of the tests. Charline Soraru contributed to the microbiological studies. 


\section{Funding Sources}

Funding from CARNOT MICA under the PLASMOTEX project.

\section{ACKNOWLEDGMENT}

This work is part of the PLASMOTEX project funded by the CARNOT MICA (Materials Institute Carnot Alsace). A. Rach and M. Wolf (ICPEES) are thanked for their contributions on the photocatalytic test setup. F. Courtier and M. Basler (ICS) are both acknowledged for the implementation of the illumination chamber for EPR characterization of the films.

\section{REFERENCES}

1 Teoh, W.Y.; Amal, R.; Scott, J. Progress in Heterogenous Photocatalysis: From Classical Radical Chemistry to Engineering Nanomaterials and Solar Reactors. J. Phys. Chem. Lett. 2012, 3, 629-639.

2 Dionysiou, D. D.; Li Puma, G.; Ye, J.; Schneider, J.; Bahnemann D. (Eds.), Photocatalysis: Applications, RSC Energy \& Environment Series N 15 , The Royal Society of Chemistry, Cambridge, UK, 2016, 436 p.

3 Ohtani, B. Photocatalysis A to Z : What We Know and What We Do Not Know in a Scientific Sense. $J$. Photochem. Photobiol. C: Photochem. Rev. 2010, 11(4), 157-178.

4 Agrios, A. G.; Pichat, P. State of the Art and Perspectives on Materials and Applications of Photocatalysis over $\mathrm{TiO}_{2}$. J. Appl. Electrochem. 2005, 35, 655-663.

5 Herrmann, J.-M. Titania-Based True Heterogeneous Photocatalysis. Environ. Sci. Pollut. Res. 2012, 19(9), 3655-3665.

6 Dionysiou, D. D.; Li Puma, G.; Ye, J.; Schneider, J.; Bahnemann D., Eds.; Photocatalysis: Fundamentals and Perspectives, RSC Energy \& Environment Series $\mathrm{N}^{\circ} 14$, The Royal Society of Chemistry, Cambridge, UK, 2016, 380 p. 
7 Robert, D.; Keller, V.; Keller, N. Immobilization of a Semiconductor Photocatalyst on Solid Supports: Methods, Materials, and Applications, In Photocatalysis and Water Purification: From Fundamentals to Recent Applications, Pichat, P., Ed., Wiley-VCH Verlag GmbH \& Co. KGaA, 2013; Chapter 5, pp $145-178$.

8 Nalajala, N.; Kumar Patra, K.; Bharad, P. A.; Gopinath, C. S. Why the Thin Film Form of a Photocatalyst is Better than the Particulate Form for Direct Solar-to-Hydrogen Conversion: A Poor Man's Approach. RSC Adv. 2019, 9, 6094-6100.

9 Wang, Y.; He, Y.; Lai, Q.; Fan, M. Review of the Progress in Preparing Nano $\mathrm{TiO}_{2}$ : An Important Environmental Engineering Material. J. Environ. Sci. 2014, 26, 2139-2177.

10 Biswas, A.; Bayer, I. S., Biris, A. S.; Wang, T.; Dervishi, E.; Faupel, F. Advances in Top-Down and Bottom-Up Surface Nanofabrication: Techniques, Applications \& Future Prospects, Adv. Colloid Interface Sci., 2012, 170(1-2), 2-27.

11 Decher, G. Fuzzy Nanoassemblies: Toward Layered Polymeric Multicomposites, Science, 1997, 277, no. $5330,1232-1237$.

12 Decher, G.; Schlenoff, J. B.; Eds.; Multilayer Thin Films: Sequential Assembly of Nanocomposite Materials, $2^{\text {nd }}$ edition. Wiley-VCH Verlag GmbH \& Co. KGaA, 2012.

13 Nunes, B. N.; Paula, L. F.; Costa, Í. A.; Machado, A. E. H.; Paterno, L. G.; Patrocinio, A. O. T. Layerby-Layer Assembled Photocatalysts for Environmental Remediation and Solar Energy Conversion', $J$. Photochem. Photobiol. C Photochem. Rev. 2017, 32, 1-20.

14 Srivastava, S.; Kotov, N. A. Composite Layer-by-Layer (LBL) Assembly with Inorganic Nanoparticles and Nanowires, Acc. Chem. Res., 2008, 41(12), 1831-1841.

15 Richardson, J. J.; Bjornmalm, M.; Caruso, F. Technology-Driven Layer-by-Layer Assembly of Nanofilms, Science, 2015, 348, no. 6233, aaa2491.

16 Quinn, J. F.; Johnston, A. P. R.; Such, G. K.; Zelikin, A. N.; Caruso, F. Next Generation, Sequentially Assembled Ultrathin Films: Beyond Electrostatics. Chem. Soc. Rev. 2007, 36, 707-718. 
17 Zhao, S.; Caruso, F.; Dähne, L.; Decher, G.; De Geest, B. G.; Fan, J.; Feliu, N. ; Gogotsi, Y.; Hammond, P. T.; Hersam, M. C.; Khademhosseini, A.; Kotov, N.; Leporatti, S.; Li, Y.; Lisdat, F.; Liz-Marzán, L. M.; Moya, S.; Mulvaney, P.; Rogach, A. L.; Roy, S.; Shchukin, D. G.; Skirtach, A. G.; Stevens, M. M.; Sukhorukov, G. B.; Weiss, P. S.; Yue, Z.; Zhu, D.; Parak, W. J. The Future of Layer-by-Layer Assembly: A Tribute to ACS Nano Associate Editor Helmuth Möhwald, ACS Nano, 2019, 13, 6151-6169

18 Ariga, K.; Ahn, E.; Park, M.; Kim, B.-S. Layer-by-Layer Assembly: Recent Progress from Layered Assemblies to Layered Nanoarchitectonics, Chem. Asian J. 2019, 14, 2553 - 2566

19 Priya, D. N.; Modak, J. M.; Raichur, A. M. LbL Fabricated Poly(Styrene Sulfonate)/TiO 2 Multilayer Thin Films for Environmental Applications. Appl. Mater. Interfaces, 2009, 11, 2684-2693.

20 Faria, A.C.R.; Vebber, M.C.; Dal'Acqua, N.; Giovanela, M.; Aguzzoli, C.; Pereira, M. B.; Machado, G.; Crespo, J. S. Characterization and Application of Self-Assembled Thin Films of Polyelectrolytes $/ \mathrm{TiO}_{2} / \mathrm{CdSe}$ for Hydrogen Production, Int. J. Hydrogen Energy 2017, 42, 16568-16578.

21 Patrocinio, A. O. T.; Paula, L. F.; Paniago, R. M. Freitag, J.; Bahnemann, D. W. Layer-by-Layer $\mathrm{TiO}_{2} / \mathrm{WO}_{3}$ Thin Films as Efficient Photocatalytic Self-Cleaning Surfaces, ACS Appl. Mater. Interfaces 2014, 6, 16859-16866.

22 Truong-Phuoc, L.; Christoforidis, K.C.; Vigneron, F.; Papaefthimiou, V.; Decher, G.; Keller, N.; Keller, V. Layer-by-Layer Photocatalytic Assembly for Solar Light-Activated Self-Decontaminating Textiles, ACS Appl. Mater. Interfaces 2016, 8, 34438-34445.

23 Chai, N. N.; Wang, H. X.; Hu, C. X.; Wang, Q.; Zhang, H. L. Well-Controlled Layer-by-Layer Assembly of Carbon Dot/CdS Heterojunctions for Efficient Visible-Light-Driven Photocatalysis, $J$. Mater. Chem. A 2015, 3, 16613-16620.

${ }^{24}$ Carré, G.; Garnier, L.; Moeller-Siegert, J.; Gies, J. P.; Keller, V.; Andre, P.; Keller, N. Antibacterial Textiles Functionalized by Layer-by-Layer Assembly of Polyelectrolytes and $\mathrm{TiO}_{2}$ Photocatalyst, $R S C$ Adv. 2015, 5, 38859-38867. 
Teh, S. J.; Lai, C. W.; Abd Hamid, S.B. Novel Layer-by-Layer Assembly of RGo-Hybridised ZnO Sandwich Thin Films for the Improvement of Photo-Catalysed Hydrogen Production, J. Energy Chem. $2016,25,336-344$.

26 Jeon, D.; Kim, H.; Lee, C.; Han, Y.; Gu, M.; Kim, B.S.; Ryu, J. Layer-by-Layer Assembly of Polyoxometalates for Photoelectrochemical (PEC) Water Splitting: Toward Modular PEC Devices, ACS Appl. Mater. Interfaces 2017, 9, 40151-40161.

27 Grandcolas, M.; Sinault, L.; Mosset, F.; Louvet, A.; Keller, N.; Keller, V. Self-Decontaminating Layerby-Layer Functionalized Textiles Based on $\mathrm{WO}_{3}$-Modified Titanate Nanotubes. Application to the Solar Photocatalytic Removal of Chemical Warfare Agents, Appl. Catal. A 2011, 391, 455-467.

28 Carp, O.; Huisman, C. L.; Reller, A. Photoinduced Reactivity of Titanium Dioxide, Prog. Solid State Chem. 2004, 32(1-2) 33-177.

29 Shibata, T.; Sakai, N.; Fukuda, K.; Ebina, Y.; Sasaki, T. Photocatalytic Properties of Titania Nanostructured Films Fabricated from Titania Nanosheets. Phys. Chem. Chem. Phys. 2007, 9, 24132420.

30 Nakajima, A.; Akiyama, Y.; Yanagida, S.; Koike, T.; Isobe, T.; Kameshima, Y.; Okada, K. Preparation

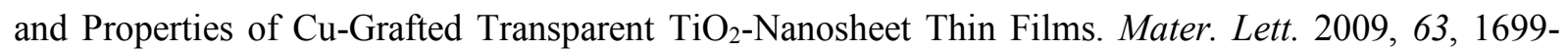
1701.

31 Liu, Z.; Zhang, X.; Nishimoto, S.; Jin, M.; Tryk, D. A.; T. Murakami, Fujishima, A. Anatase TiO 2 Nanoparticles on Rutile $\mathrm{TiO}_{2}$ Nanorods: A Heterogeneous Nanostructure via Layer-by-Layer Assembly Langmuir 2007, 23, 10916-10919.

32 Dontsova, D.; Keller, V.; Keller, N .; Steffanut, P.; Félix, O.; Decher, G. Photocatalytically Active Polyelectrolyte/Nanoparticle Films for the Elimination of a Model Odorous Gas, Macromol. Rapid Commun. 2011, 32, 1145-1149.

33 Rongé, J.; Bets, J.; Pattanaik, S.; Bosserez, T.; Borellini, S.; Sree, S. P.; Decher, G.; Martens, J.A. Tailoring Preparation, Structure and Photocatalytic Activity of Layer-by-Layer Films for Degradation of Different Target Molecules, Catal. Today 2015, 246, 28-34. 
34 Krogman, K. C.; Zacharia, N. S.; Grillo, D. M. ; Hammond, P. T. Photocatalytic Layer-by-Layer Coatings for Degradation of Acutely Toxic Agents. Chem. Mater. 2008, 20, 1924-1930.

35 Ohno, T.; Sarukawa, K.; Tokieda, K.; Matsumura, M. Morphology of a $\mathrm{TiO}_{2}$ Photocatalyst (Degussa, P-25) Consisting of Anatase and Rutile Crystalline Phases, J. Catal. 2001, 203, 82-86.

36 Ohtani, B.; Prieto-Mahaney, O. O.; Li, D.; Abe, R. What is Degussa (Evonik) P25? Crystalline Composition Analysis, Reconstruction from Isolated Pure Particles and Photocatalytic Activity Test, Journal of Photochemistry and Photobiology A: Chemistry 2010, 216, 179-182.

37 Muggli, D. S.; Backes, M. J. Two Active Sites for Photocatalytic Oxidation of Formic Acid on $\mathrm{TiO}_{2}$ : Effects of $\mathrm{H}_{2} \mathrm{O}$ and Temperature, J. Catal. 2002, 209(1), 105-113.

38 Nielsen, G. D.; Hansen, L. F.; Andersen, B.; Poulsen, N.; Melchior, O. Indoor Air Guideline Levels for Formic, Acetic, Propionic and Butyric Acid, Indoor Air, 1998, 8, no. S5, 8-24.

39 Tompkins, H. G.; Irene, E. A. Handbook of Ellipsometry, William Andrew Publishing, Springer-Verlag GmbH \& Co. KG, 2005.

40 Sauerbrey, G. Z. The Use of Quartz Oscillators for Weighing Thin Layers and for Microweighing. Z. Phys A: Hadrons Nucl. 1959, 155(2), 206-222.

41 Tan, Y. P.; Yildiz, U. H.; Wei, W.; Waite, J. H.; Miserez, A. Layer-by-Layer Polyelectrolyte Deposition: A Mechanism for Forming Biocomposite Materials, Biomacromolecules 2013, 14(6), 1715-1726.

42 Colbeau-Justin, C. ; Kunst, M. ; Huguenin, D. Structural Influence on Charge-Carrier Lifetimes in $\mathrm{TiO}_{2}$ Powders Studied by Microwave Absorption J. Mater. Sci. 2003, 38, 2429-2437.

43 Kouamé, N. A.; Tahiri Alaoui, O.; Alexandre Herissan, A.; Larios, E.; Yacaman, M.-J.; Etcheberry, A.; Colbeau-Justin, C.; Remita, H. Visible Light-Induced Photocatalytic Activity of Modified Titanium(IV) Oxide With Zero-Valent Bismuth Clusters. New J. Chem. 2015, 39, 2316.

44 Sengele, A.; Robert, D.; Keller, N.; Colbeau-Justin, C.; Keller, V. Sn-Doped and Porogen-Modified $\mathrm{TiO}_{2}$ Photocatalyst for Solar Light Elimination of Sulfure Diethyle as a Model for Chemical Warfare agent. Appl. Catal. B: Environ. 2019, 245, 279-289. 
45 Twardoch, M.; Messai, Y.; Vileno, B.; Hoarau, Y.; Mekki, D.; Felix, O.; Turek, P.; Weiss, J.; Martel, D. Development of an Electron Paramagnetic Resonance Methodology for Studying the PhotoGeneration of Reactive Species in Semiconductor Nano-Particle Assembled Films, Mol. Phys., 2018, $116,1558-1554$.

46 Mills, A.; Hill, C.; Robertson, P. K. J. Overview of the Current ISO Tests for Photocatalytic Materials, Journal of Photochemistry and Photobiology A: Chemistry 2012, 237, 7- 23.

47 Yan, Y.; Keller, V.; Keller, N. On the Role of Bmimpf 6 and P/F- Containing Additives in the Sol-Gel Synthesis of $\mathrm{TiO}_{2}$ Photocatalysts with Enhanced Activity in the Gas Phase Degradation of Methyl Ethyl Ketone, Appl. Catal. B: Environ. 2018, 234, 56-69.

48 De Lasa, H.; Serrano, B.; Salaices, M. The Energy Efficiency Factors in Photocatalytic Processes, In Photocatalytic reaction engineering, De Lasa, H.; Serrano, B.; Salaices, Eds. Springer, pp. 119-123.

49 Yan, Y.; Soraru, C.; Keller, V.; Keller, N. ; Ploux, L. Antibacterial and Biofilm-Preventive Photocatalytic Activity and Mechanisms on P/F-Modified $\mathrm{TiO}_{2}$ Coatings. ACS Appl. Bio Mater. 2020, 3(9), 5687-5698.

50 Miao, H.; Ratnasingam, S.; Pu, C. S.; Desai, M. M.; Sze, C. C. Dual Fluorescence System for Flow Cytometric Analysis of Escherichia Coli Transcriptional Response in Multi-Species Context. Journal of Microbiological Methods 2009, 76 (2), 109-119.

51 Cano-Casanova, L.; Amorós-Pérez, A.; Ouzzine, M.; Lillo-Ródenas, M. A.; Román-Martínez, M. C. One Step Hydrothermal Synthesis of $\mathrm{TiO}_{2}$ with Variable $\mathrm{HCl}$ Concentration: Detailed Characterization and Photocatalytic Activity in Propene Oxidation, Appl. Catal. B: Environ. 2018, 220, 645-653.

52 Kommireddy, D. S.; Patel, A. A.; Shutava, T. G.; Mills, D. K.; Lvov, Y. M. Layer-by-Layer Assembly of $\mathrm{TiO}_{2}$ Nanoparticles for Stable Hydrophilic Biocompatible Coatings, J. Nanosci. Nanotechnol. 2005, 5(7), 1081-1087.

53 Jung, S.-C.; Kim, S.-J.; Imaishi, N.; Cho, Y.-I. Effect of $\mathrm{TiO}_{2}$ Thin Film Thickness and Specific Surface Area by Low-Pressure Metal-Organic Chemical Vapor Deposition on Photocatalytic Activities, Appl. Catal. B: Env. 2005, 55(4), 253-257. 
Herrmann, J.-M. Photocatalysis Fundamentals Revisited to Avoid Several Misconceptions. Appl. Catal. B: Env. 2010, 99, 461-468

55 Fox, M. A.; Dulay, M. T. Heterogeneous Photocatalysis, Chem. Rev. 1993, 93(1), 341-357.

56 Matsumoto, K.; Nagata, K.; Yamamoto, H.; Endo, K.; Anzai, K.; Aoki, I. Visualization of Free Radical Reactions in an Aqueous Sample Irradiated by $290 \mathrm{MeV}$ Carbon Beam, Magn. Reson. Med., 2009, 61(5), $1033-1039$.

${ }^{57}$ Montag, D.; Frant, M.; Horn, H.; Liefeith, K. Dependence of theIinitial Adhesion of Biofilm Forming Pseudomonas putida mt2 on Physico-chemical Material Properties, Biofouling, 2012, 28 (3), 315-327.

58 Sherbet, G. V.; Lakshmi, M. S. Characterisation of Escherichia coli Cell Surface by Isoelectric Equilibrium Analysis, Biochim. Biophys. Acta, 1973, 298(1), 50-58.

59 Beyth, N.; Kesler Shvero, D.; Zaltsman, N.; Houri-Haddad, Y.; Abramovitz, I.; Davidi, M. P.; Weiss, E. I. PLoS One 2013, 8, e 78586.

${ }^{60}$ Felix, O.; Zheng, Z.; Cousin, F.; Decher, G. Are Sprayed LbL-Films Stratified? A First Assessment of the Nanostructure of Spray-Assembled Multilayers by Neutron Reflectometry, C. R. Chimie, 2009, 12, 225-234.

${ }^{61}$ Jacoby, W. A.; Maness, P. C.; Wolfrum, E. J.; Blake, D. M.; Fennell, J. A. Mineralization of Bacterial Cell Mass an a Photocatalytic Surface in Air. Environ. Sci. Technol. 1998, 32(17), 2650-2653.

${ }^{62}$ Karbasi, M.; Karimzadeh, F.; Raeissi, K.; Rtimi, S.; Kiwi, J.; Giannakis, S.; Pulgarin, C. Insights Into the Photocatalytic Bacterial Inactivation by Flower-Like $\mathrm{Bi}_{2} \mathrm{WO}_{6}$ Under Solar or Visible Light, Through In Situ Monitoring and Determination of Reactive Oxygen Species (ROS). Water 2020, 12, 1099.

63 Xianyu, W. X.; Park, M. K.; Lee, W. I.; Thickness Effect in the Photocatalytic Activity of $\mathrm{TiO}_{2}$ Thin Films Derived from Sol-Gel Process. Korean Journal of Chemical Engineering 2001, 18, 903-907.

64 Liao, L.-F.; Wu, W.-C.; Chen, C.-Y.; Lin, J.-L. Photooxidation of Formic Acid vs Formate and Ethanol vs Ethoxy on $\mathrm{TiO}_{2}$ and Effect of Adsorbed Water on the Rates of Formate and Formic Acid Photooxidation. J. Phys. Chem. B 2001, 105, 7678-7685. 
Popova, G. Y.; Andrushkevich, T. V.; Chesalov, Y. A.; Stoyanov, E. S. In Situ FTIR Study of the Adsorption of Formaldehyde, Formic Acid, and Methyl Formiate at the Surface of $\mathrm{TiO}_{2}$ (Anatase), Kinetics and Catalysis 2000, 41(6), 805-811.

${ }^{66}$ Nanayakkara, C. E.; Dillon, J. K.; Grassian, V. H. Surface Adsorption and Photochemistry of Gas-Phase Formic Acid on $\mathrm{TiO}_{2}$ Nanoparticles: The Role of Adsorbed Water in Surface Coordination, Adsorption Kinetics, and Rate of Photoproduct Formation. J. Phys. Chem. C 2014, 118(44), 25487-25495.

${ }^{67}$ Kim, T.-H.; Sohn, B.-H. Photocatalytic Thin Films Containing $\mathrm{TiO}_{2}$ Nanoparticles by the Layer-byLayer Self-Assembly Method, Appl. Surf. Sci. 2002, 201(1), 109-114.

${ }^{68}$ v. Klitzing, R.; Wong, J. E.; Jaeger, W.; Steitz. R. Short Range Interactions in Polyelectrolyte Multilayers. Curr. Opin. Colloid Interface Sci. 2004, 9, 158-162.

${ }^{69}$ Lavalle, P.; Vivet, V.; Jessel, N.; Decher, G.; Voegel, J.-C.; Mesini, P. J.; Schaaf, P. Direct Evidence for Vertical Diffusion and Exchange Processes of Polyanions and Polycations in Polyelectrolyte Multilayer Films, Macromolecules 2004, 37(3), 1159-1162.

70 Lavalle, P.; Picart, C.; Mutterer, J.; Gergely, C.; Reiss, H.; Voegel, J.-C.; Senger, B.; Schaaf, P. Modeling the Buildup of Polyelectrolyte Multilayer Films Having Exponential Growth, The Journal of Physical Chemistry B 2004, 108(2), 635-648.

71 Kolasinska, M.; Gutberlet, T.; Krastev, R. Ordering of $\mathrm{Fe}_{3} \mathrm{O}_{4}$ Nanoparticles in Polyelectrolyte Multilayer Films, Langmuir, 2009, 25(17), 10292-10297. 


\section{Supporting information}

\section{Virtually Transparent $\mathrm{TiO}_{2} /$ Polyelectrolyte Thin}

\section{Multilayer Films as High Efficiency Nanoporous}

\section{Photocatalytic Coatings for Breaking Down}

\section{Formic Acid and for E. Coli Removal}

Marvin Motay, ${ }^{a, b}$ David Martel, ${ }^{b}$ Bertrand Vileno, ${ }^{c}$ Charline Soraru, ${ }^{d}$ Lydie Ploux, ${ }^{, e}$ María Guadalupe Méndez-Medrano, ${ }^{f}$ Christophe Colbeau-Justin, ${ }^{f}$ Gero Decher, ${ }^{b}$ Nicolas Keller ${ }^{a} * *$

a Institut de Chimie et Procédés pour l'Energie, l'Environnement et la Santé (ICPEES),

CNRS, Université de Strasbourg, 25 rue Becquerel 67087 Strasbourg, France

b Institut Charles Sadron (UPR 22), CNRS, Université de Strasbourg, 23 rue de Loess, 67034, Strasbourg Cedex 2, France

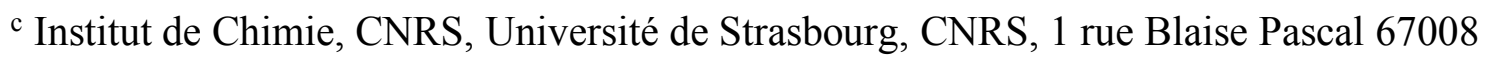
Strasbourg Cedex, France

d Institut de Science des Matériaux de Mulhouse (IS2M, UMR7361 CNRS/Université de Haute Alsace), 15 rue Jean Starcky, 68057 Mulhouse, France

e Biomaterial Bioengineering (U1121 INSERM/Université de Strasbourg), 11 rue Humann, 67000 Strasbourg, France

${ }^{\mathrm{f}}$ Institut de Chimie, CNRS UMR 8000, Université Paris-Saclay, 91405 Orsay, France corresponding author:*nkeller@unistra.fr 


\section{Supporting Information}

SI1 Substrate preparation

SI2 Quartz Crystal Microbalance with Dissipation monitoring (QCM-D) measurement

SI3 UV-Visible spectrophotometry in transmission mode

SI4 Time Resolved Microwave Conductivity (TRMC)

SI5 EPR characterization of multilayer films

SI6 Schematic single-pass photocatalytic reactor used for the gas phase photocatalytic tests

Figure S1 XRD characterization of Aeroxide $\mathrm{TiO}_{2} \mathrm{P} 25$ suspensions and of multilayer films

Figure S2 DLS characterization of the Aeroxide $\mathrm{TiO}_{2}$ P25 suspension used for the LbL film construction

Figure S3 ICP-AES chemical analysis of the multilayer films

Figure S4 QCM-D measurements

Figure S5 Stability of films during the test protocols used for bacterial assays and control sample results

Table S1 Amount of deposited materials on LbL film calculated with QCM-D data from the $3^{\text {rd }}$ overtone.

Table S2 Evolution of the multilayer film thickness after being immerged in a $9 \mathrm{~g} / \mathrm{l} \mathrm{NaCl}$ solution, obtained by ellipsometry

Table S3 HCOOH conversion obtained on specific architectures of films in comparison to that achieved on the $\mathrm{PEI} /\left(\mathrm{PSS} / \mathrm{TiO}_{2}\right)$ reference film with one single layer pair. 


\section{Supporting Information SI1}

\section{Substrate preparation}

Silicon wafers $(4.5 \times 8 \mathrm{~cm})$, glass $(2.5 \times 4.5 \mathrm{~cm})$ and quartz slides $(1.2 \times 3.2 \mathrm{~cm})$ were prepared as follows. The substrates were immersed in a $2 \% \mathrm{v} / \mathrm{v}$ Hellmanex solution in distilled water and sonicated (ultrasound bath) for $15 \mathrm{~min}$. The substrates were then rinsed with copious amounts of distilled water and then immersed in an ethanol-Milli Q water solution (50:50 v/v) and sonicated for $15 \mathrm{~min}$. The substrates were then dried using compressed air and activated for 3 min using an oxygen plasma (Plasma Cleaner, Harick Plasma, New York, USA), with a power of 10,2 W applied to the radiofrequency coil. This process was repeated twice for quartz slides in order to activate both sides of the slides for UVVisible spectroscopy characterisations. All substrates were used straight after plasma activation.

Gold coated quartz crystals for a quartz crystal microbalance with dissipation monitoring (QCM-D) were prepared by activating them with a $\mathrm{UV} / \mathrm{O}_{3}$ activator $\left(\mathrm{UV} / \mathrm{O}_{3}\right.$ ProCleaner ${ }^{\mathrm{TM}}$, BioForce NanoSciences, Ames, USA) for 20 min. Gold coated quartz crystals were used straight after activation. 


\section{Supporting Information SI2}

\section{Quartz Crystal Microbalance with Dissipation monitoring (QCM-D) measurement.}

QCM-D measurements were carried out on the LbL films in a QCM-D E4 (Q-Sense AB, Sweden) using flow modules in parallel. In situ $\mathrm{LbL}$ assemblies of $\mathrm{TiO}_{2}$ nanoparticles and polyelectrolytes were done in a similar manner to those on macroscopic silicon or glass/quartz substrates except that for QCM$\mathrm{D}$, the $\mathrm{LbL}$ assembly was done in parallel. The polyelectrolyte solutions and the $\mathrm{TiO}_{2}$ suspensions were injected into the cell $(600 \mu 1$ at a $300 \mu 1 / \mathrm{min}$ flow) and the solutions/suspensions were kept onto the substrates until stabilisation (full adsorption) was obtained. The substrates were rinsed by injecting 3 times Milli-Q water or acid Milli-Q water (according to the used solution or suspension) and the deposition steps were repeated for building the LbL film. 


\section{Supporting Information SI3}

\section{UV-Visible spectrophotometry in transmission mode}

UV-Visible (UV-Vis) spectroscopy provides information on the absorption properties of a sample. It is based on the intensity of a monochromatic radiation once it passes through (transmission mode) or reflects (reflection mode) from the sample, compared to the initial intensity. In liquid media, the absorbance measured by UV-Vis spectroscopy is related to the amount of molecules in the media being passed through by the light according to the Beer-Lambert Law:

$$
A=\log \left(\frac{I}{I_{0}}\right)=\varepsilon \times l \times c
$$

where $\mathrm{A}$ is the absorbance or extinction of the molecules, $\mathrm{c}$ is the concentration of molecules in the media, 1 is the optical pathway corresponding to the cell length, $\varepsilon$ is the extinction coefficient and $\mathrm{I}_{0}$ and I are the intensity of the incident light and transmitted light respectively.

UV-visible spectroscopy in transmission mode was used in order to monitor the film construction on quartz slides. Here the optical pathway, 1 , corresponds to the thickness of the quartz slide. Since the film thicknesses are within the nanometric range, the film thickness is negligible in the optical pathway.

By neglecting the light scattering and assuming identical extinction values of $\mathrm{TiO}_{2}$ in aqueous suspension and in LbL titania films deposited on quartz slide, the absorbance of the titania film can be correlated to the amount of titania per layer deposited using the following equation (Dontsova et al.) :

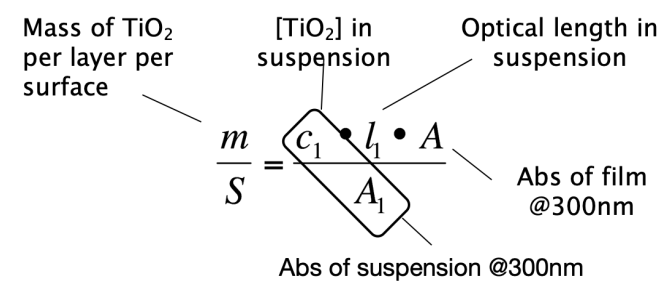

here the $\mathrm{m} / \mathrm{S}$ ratio corresponds to the mass of catalyst deposited per layer per surface area $\left(\mathrm{g} / \mathrm{m}^{2}\right)$. $\mathrm{A}_{1}$ is the suspension absorbance and $\mathrm{A}$ is the absorbance of one layer of the deposited material (all absorbance measurements were made at $300 \mathrm{~nm}$, see Figure 5 in the article). $\mathrm{c}_{1}$ is the concentration of the titania suspension $\left(\mathrm{g} / \mathrm{m}^{3}\right), 1_{1}$ the width of the quartz slide. 
The absorbance of the $\mathrm{TiO}_{2}$ suspension $\left(\mathrm{A}_{1}\right)$ can be calculated through the establishment of a calibration curve of the $\mathrm{TiO}_{2}$ suspension absorbance against the $\mathrm{TiO}_{2}$ suspension concentration (left). The estimated amount of titania deposited per layer, derived from right graph, was found to be $47 \pm 5$ $\mathrm{mg} / \mathrm{m}^{2}\left(4.7 \pm 0.5 \mu \mathrm{g} / \mathrm{cm}^{2}\right)$.
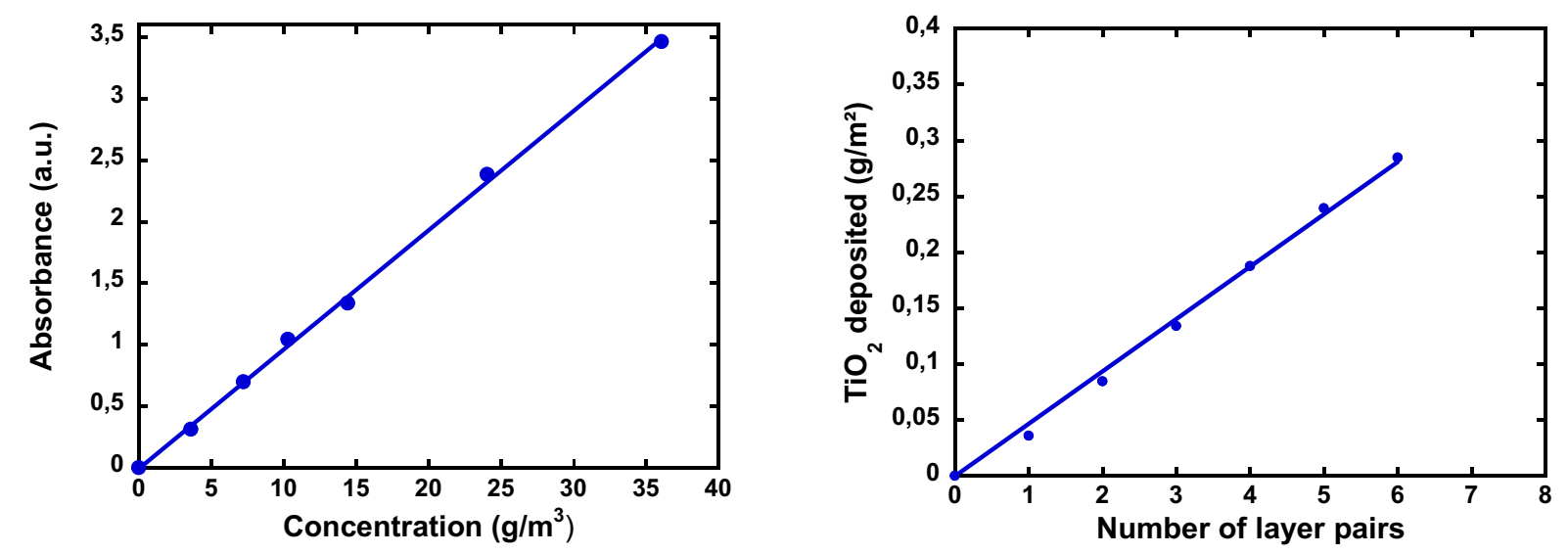

(left) Absorbance of the $\mathrm{TiO}_{2}$ suspension in regards to the $\mathrm{TiO}_{2}$ concentration ; (right) amount of $\mathrm{TiO}_{2}$ deposited per layer pairs calculated from Dontsova's equation.

$$
m=V \times d \times f
$$

with $m$ the mass of $\mathrm{TiO}_{2}, V$ the volume of a monolayer with an apparent surface of $1 \mathrm{~m}^{2}, f$ the filling coefficient and $d$ the density of $\mathrm{TiO}_{2}$ at $4 \times 10^{+6} \mathrm{~g} / \mathrm{m}^{3}$.

Here, with a monolayer thickness of $40 \mathrm{~nm}$, the volume of a monolayer is $V=1 \times 1 \times 40 \times 10^{-9}=$ $40 \times 10^{-9} \mathrm{~m}^{3}$

Considering a $\mathrm{TiO}_{2}$ amount $m$ of $47 \mathrm{mg} / \mathrm{m}^{2}$ derived from spectrophotometry (or of $70 \mathrm{mg} / \mathrm{m}^{2}$ when derived from ICP-AES, see Figure S4), the filling coefficient $f$ was calculated as 0.29 or 0.44 , respectively. This corroborated the highly porous structure of the film.

- D. Dontsova, V. Keller, N. Keller, P. Steffanut, O. Félix, G. Decher, Photocatalytically Active Polyelectrolyte/Nanoparticle Films for the Elimination of a Model Odorous Gas, Macromol. Rapid Commun., 32(15) (2011) 1145-1149. 


\section{Supporting Information SI4}

\section{Time Resolved Microwave Conductivity (TRMC)}

The charge-carrier lifetimes in the LbL films upon UV illumination were determined by microwave absorption experiments using the TRMC method ${ }^{1,2}$. The TRMC technique is based on the measurement of the change of the microwave power reflected by a sample, $\Delta P(t)$, induced by its laser pulsed illumination. The relative difference $\Delta P(t) / P$ can be correlated, for small perturbations of conductivity, to the difference of the conductivity $\Delta \sigma(t)$ considering the following equation:

$$
\frac{\Delta P(t)}{P}=A \Delta \sigma(t)=A e \sum_{i} \Delta n_{i}(t) \mu_{i}
$$

where $\Delta n_{i}(t)$ is the number of excess charge-carriers $i$ at time $t$ and $\mu_{i}$ their mobility. The sensitivity factor $\mathrm{A}$ is independent of time, but depends on different factors such as the microwave frequency or the dielectric constant. Considering that the trapped species have a small mobility, which can be neglected, $\Delta n_{i}$ is reduced to mobile electrons in the conduction band and holes in the valence band. And in the specific case of $\mathrm{TiO}_{2}$, the TRMC signal can be attributed to electrons because their mobility is much larger than that of the holes ${ }^{3}$. The incident microwaves were generated by a Gunn diode of the $\mathrm{K}_{\alpha}$ band at $30 \mathrm{GHz}$. Pulsed light source was an OPO laser (EKSPLA, NT342B) tunable from 225 to $2000 \mathrm{~nm}$. It delivers $8 \mathrm{~ns}$ fwmh pulses with a frequency of $10 \mathrm{~Hz}$. The light energy density received by the sample was $1.3 \mathrm{~mJ} \mathrm{~cm}^{-2}$ at $350 \mathrm{~nm}$. The main data provided by TRMC are the maximum value of the signal $\left(I_{\max }\right)$, which indicates the number of the excess charge carriers created by the pulse, including decay processes during the excitation by the laser $(10 \mathrm{~ns})$, and the decay $(I(t))$ due to the decrease of the excess electrons, either by recombination or by trapping processes. Concerning the decay, i.e. the lifetime of charge carriers, a short and a long range is usually analysed. The shortrange decay, arbitrarily fixed up to $40 \mathrm{~ns}$ after the beginning of the pulse, represented by the $\mathrm{I}_{40 \mathrm{~ns}} / \mathrm{I}_{\max }$ ratio, reflects fast processes, mainly recombination of charge carriers, a high value indicating a low recombination speed. 
1. Colbeau-Justin, C. ; Kunst, M. ; Huguenin, D. Structural influence on charge-carrier lifetimes in $\mathrm{TiO}_{2}$ powders studied by microwave absorption J. Mater. Sci. 2003, 38, 2429-2437.

2. Tahiri Alaoui, O. A. ; Herissan, C. ; Le Quoc, C. ; Zekri, M. E. M.; Sorgues, S. ; Remita, H. ; Colbeau-Justin, C. Elaboration, charge-carrier lifetimes and activity of $\mathrm{Pd}^{-\mathrm{TiO}_{2}}$ photocatalysts obtained by gamma radiolysis. J. Photochem. Photobiol. A 2012, 242, 34-43.

3. Fonash, S. J. Solar Cell Device Physics, Academic Press, New-York, London, 1981. 


\section{Supporting Information SI5}

\section{EPR characterization of multilayer films}

LbL film construction. Capillaries were cleaned with ethanol/water $(50 / 50 \mathrm{v} / \mathrm{v})$ in low density sonicating bath for $15 \mathrm{~min}$. They were rinsed with water and dried upon airflow. The clean substrates were first dipped $20 \mathrm{~min}$ in a solution of polycation PEI followed by rinsing step (dipping 3 times of 3 $\min$ in 3 different containers of ultrapure water (18M $\Omega . c m$, Milli-Qlab system). The next steps involved alternative stages of dipping capillaries of polyanion PSS solution (20 min in $\mathrm{HNO}_{3}$ solution adjusted $\mathrm{pH}=2.5)$ and in the $\mathrm{TiO}_{2}$ suspension adjusted by $\mathrm{HNO} 3$ to $\mathrm{pH} 2.5$ (20 min). After each dipping steps, a rinsing step, dipping 3 times of 3 min in 3 different containers of $\mathrm{HNO}_{3}$ solution $(\mathrm{pH}=2.5)$, was performed.

Except for PEI, which was only used as first deposit, all the dipping (PSS or $\mathrm{TiO}_{2}$ ) and rinsing steps were repeated to reach the desired film configuration $(\mathrm{PEI} / \mathrm{PSS}) /\left(\mathrm{TiO}_{2} / \mathrm{PSS}\right)_{\mathrm{n}-1}-\left(\mathrm{TiO}_{2}\right)_{\mathrm{n}}$ with $\mathrm{n}=1,3,5$, 7, 10. Once films were constructed a final rinsing step in ultrapure water $(3 \times 5 \mathrm{~min}$ in 3 different containers) was performed. The last stage of the procedure was to clean the outside of the capillaries with an optical tissue soaked of ethanol in order to remove the films built.
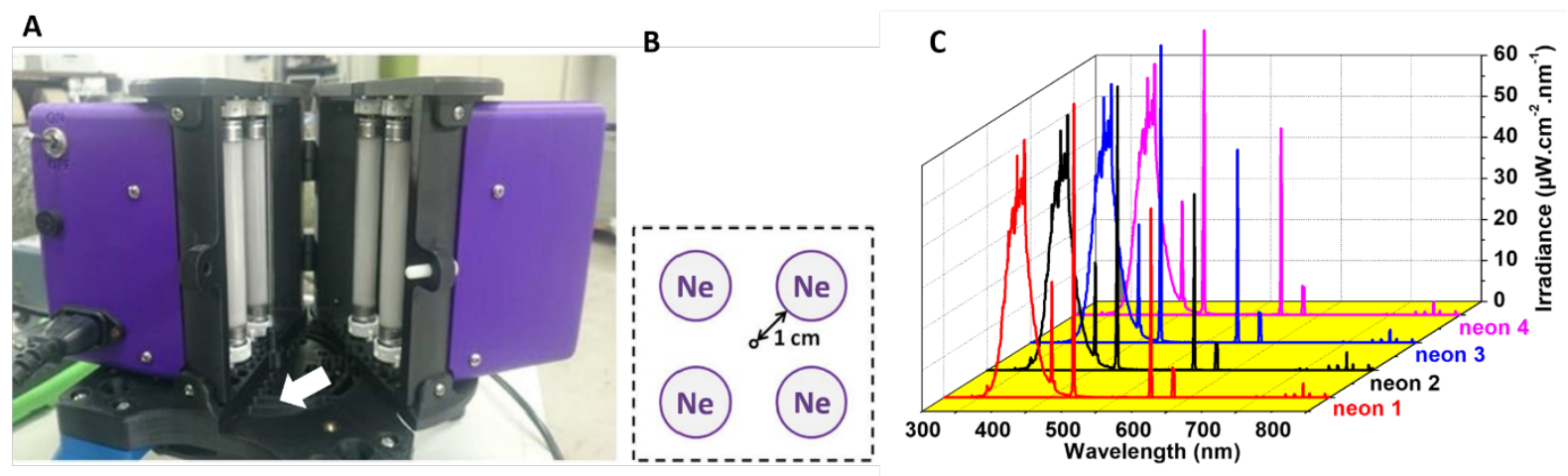

(A) Open view of the irradiation chamber equipped with a cooling fan underneath (white arrow) and composed of 4 UV-A neon tubes surrounding a clear fused quartz tube (Wilmad, 705-PQ-6.25) positioned at $1 \mathrm{~cm}$ of each neon allowing to centered the capillary with respect to the light source. (B) 
schematic top view of the closed irradiation chamber. (C) Irradiance spectra of the 4 UV-A neon tubes used for illumination of functionalized capillaries.

Electron Paramagnetic Resonance (EPR). The coated capillaries were filled with $50 \mu \mathrm{L}$ nondeoxygenated TEMPOL solution in water at $200 \mu \mathrm{M}$ and sealed. A first spectrum was recorded to reach the initial EPR intensity $\left(\mathrm{I}_{0}\right)$. For all measurements, the variations of the $\mathrm{I}_{0}$ values are less than $3 \%$. Then, successive illumination steps of $30 \mathrm{~s}$ were applied. Between each illumination step, one $\mathrm{I}(\mathrm{t})$ spectrum was recorded. All the intensities values, proportional to the TEMPOL concentration $(\mathrm{I} \propto[\mathrm{T} \bullet])$, were obtained after baseline correction and double integrations. EPR data were plotted as $\mathrm{I} / \mathrm{I}_{0} v s$. illumination time. Noteworthy, without the presence of paramagnetic probe, no EPR signal is detected.

Illumination of the capillaries was performed outside the EPR cavity with an UV neon-based labmade illumination chamber. Each neon presents a $\lambda_{\max }=365 \mathrm{~nm}(\mathrm{~h} v=3.4 \mathrm{eV})$ and $\mathrm{E} \approx 1.5 \mathrm{~mW} \cdot \mathrm{cm}^{-2}$ (at $c a .1 \mathrm{~cm}$ distance measured with a powermeter 1936-C and a 918D-UV-OD3 detector from Newport). The emission spectra of the neons and a schematic description of the experimental setup are depicted above. As TEMPOL does not absorb at this wavelength, there is no absorption variation during measurement. Electronic photo-generation processes occur only during the irradiation procedure and are assumed to stop as soon as light is off. All experiments were performed at room temperature (295 \pm $1 \mathrm{~K})$. 


\section{Supporting Information SI6}

\section{Schematic single-pass photocatalytic reactor used for the gas phase photocatalytic tests}

The photocatalytic reactor was derived from that proposed in the ISO 22197 standard series. This reactor consisted of an aluminium chamber (260 mm in length $\mathrm{x} 50 \mathrm{~mm}$ in width $\mathrm{x} 40 \mathrm{~mm}$ in height) closed with a quartz window. A polytetrafluoroethylene (PTFE) support is located inside the aluminium chamber on which the pollutant flow passes. LbL films constructed on model surfaces (silicon wafers) and textiles were placed face-up in a cavity located at the centre of the PTFE support. LbL films built on $36 \mathrm{~cm}^{2}$ silicon wafer were directly located in the cavity.

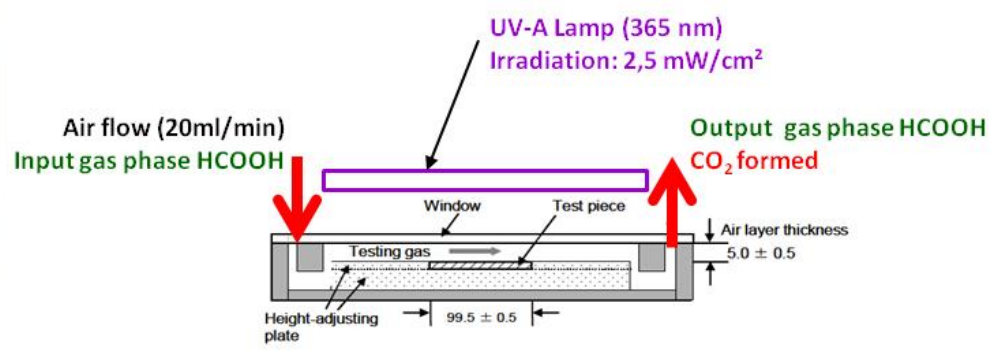

Schematic representation of the single-pass reactor containing a LbL film built on silicon wafer

A 8W UV-A lamp (Sylvania Blacklight Blue F8W/BLB T5) with a spectral peak centred at $365 \mathrm{~nm}$ was placed above the reactor $(1.5 \mathrm{~cm})$, parallel to the photocatalytic film. An irradiance of $2.5 \mathrm{~mW} / \mathrm{cm}^{2}$ was measured at the top of the sample surface. The photocalytic reactor was placed in a thermostated chamber for maintaining a constant temperature of $25^{\circ} \mathrm{C}$ during the test according to ISO standards, since heat generated by the lamp during the irradiation could not be neglected.

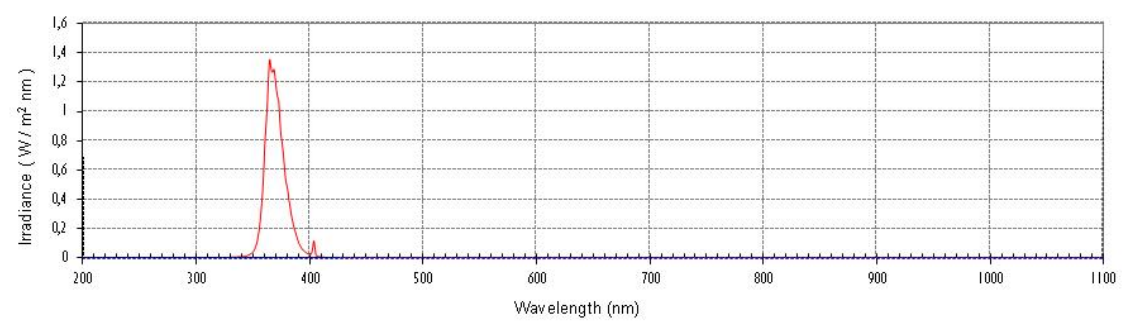

Irradiance spectrum of the UV-A lamp used in this work 
The generation of the inlet polluted air flow was obtained by mixing three synthetic air flows: (i) dry air flow, (ii) humid air flow, (iii) gas-phase $\mathrm{HCOOH}$ containing air flow. Synthetic air was bubbled in a temperature-controlled saturator containing liquid phase formic acid $(\mathrm{HCOOH}$, Sigma Aldrich, $>95 \%)$ at $15^{\circ} \mathrm{C}$ and atmospheric pressure. Thus, the concentration of gas phase $\mathrm{HCOOH}$ was related to the vapour pressure of $\mathrm{HCOOH}$ at working temperature and pressure conditions. In the same way, synthetic air was bubbled in distilled water at $25^{\circ} \mathrm{C}$ and atmospheric pressure. Concentration in the gas phase was set by the vapour pressure in the working conditions. Water partial pressure was expressed in terms of relative humidity $(\mathrm{RH}): 100 \%$ of $\mathrm{RH}$ being defined as vapour pressure at $25^{\circ} \mathrm{C}$ and atmospheric pressure. These two air flows were then mixed with an additional synthetic air flow (dry air) to obtain the required pollutant-water-air ratio with a constant total air rate of $20 \mathrm{ml} / \mathrm{min}$, corresponding to a velocity of 0.74 $\mathrm{cm} / \mathrm{s}^{-1}$ and a residence time of $10.8 \mathrm{~s}$ in the reaction zone of the reactor. Brooks 5850 massflow meters were used to control separately dry and humid air flows. Relative humidity was set at $50 \%$ (about $3 \%$ relative to the total atmospheric pressure). In-Flow Bronkhorst flow meter (Bronkhorst ${ }^{\circledR}$ High-Tech, the Netherlands) allowed the control of $\mathrm{HCOOH}$ containing air flow and the photocatalytic tests were implemented at a gas phase $\mathrm{HCOOH}$ concentration of $45 \mathrm{ppm}_{\mathrm{v}}$. 


\section{Figure S1}

XRD characterization of Aeroxide $\mathrm{TiO}_{2} \mathrm{P} 25$ suspensions and of multilayer films
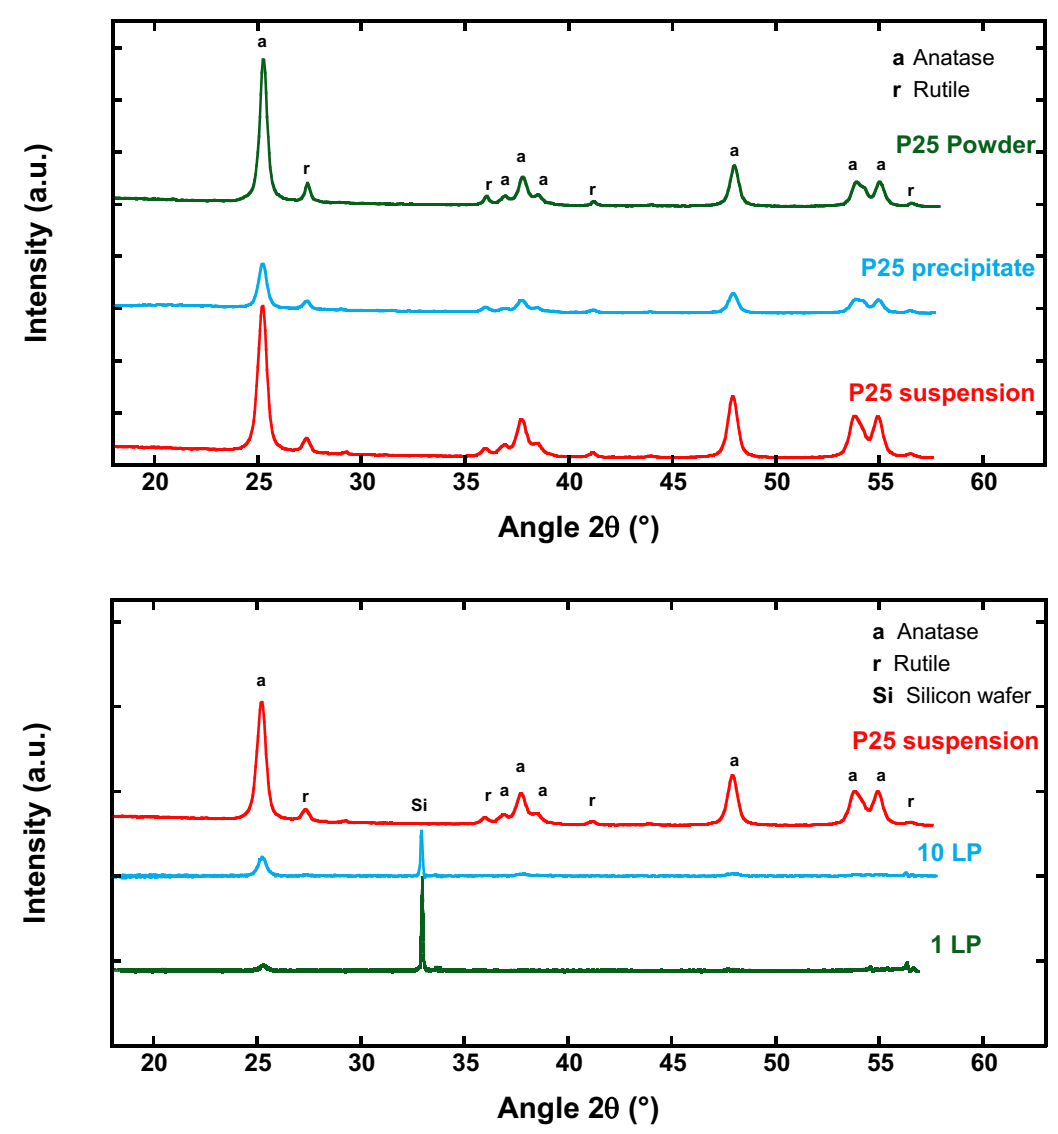

Figure S1 : XRD analysis of (top) $\mathrm{TiO}_{2} \mathrm{P} 25$ as powder and from both the precipitate and the LbL suspension, (bottom) the titania and polyelectrolytes LbL films with 1 and 10 layer pairs, compared to the $\mathrm{TiO}_{2} \mathrm{P} 25$ powder from the $\mathrm{Lbl}$ suspension. 


\section{Figure S2}

\section{DLS characterization of the Aeroxide $\mathrm{TiO}_{2}$ P25 suspension used for the $\mathrm{LbL}$ film}

construction

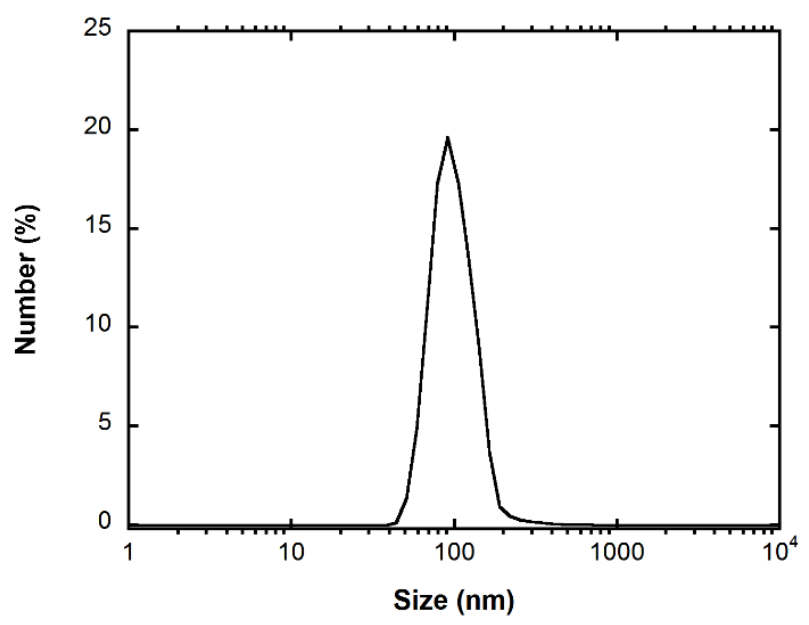

Figure S2 : Dynamic light scattering characterisation of the $\mathrm{TiO}_{2} \mathrm{P} 25$ suspension used for LbL film construction. 
Figure S3

QCM-D measurements

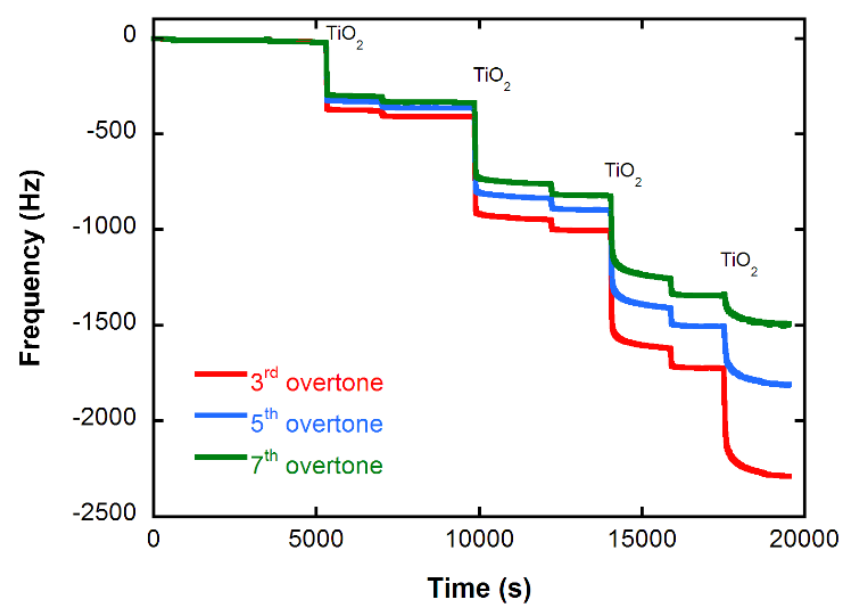

Figure S3. Change of frequency overlaying of $3^{\text {rd }}, 5^{\text {th }}$ and $7^{\text {th }}$ overtones when a 4 layer pair $\mathrm{PEI}\left(\mathrm{PSS} / \mathrm{TiO}_{2}\right)_{4}$ film is constructed on the QCM quartz slide. 


\section{Figure S4}

\section{ICP-AES chemical analysis of the multilayer films}

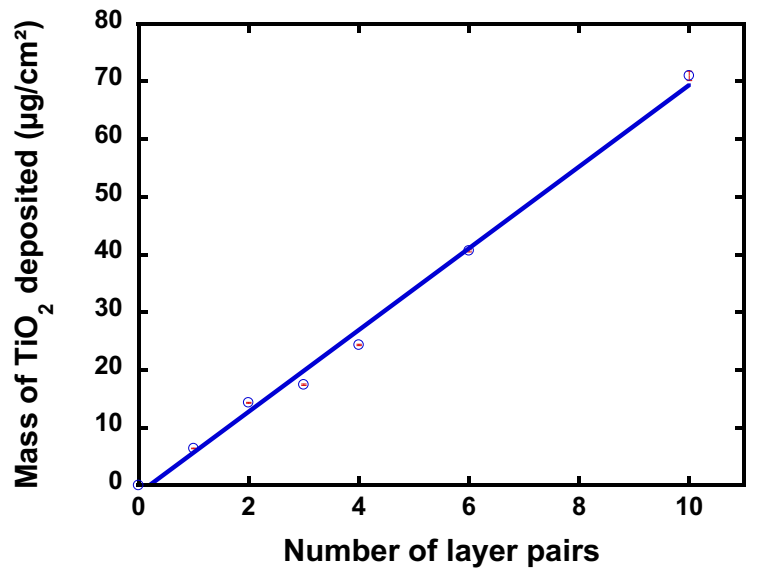

Figure S4 : Mass of $\mathrm{TiO}_{2}$ deposited investigated by chemical analysis ICP-AES. Error bars are too small to be clearly shown on the graph. 


\section{Figure S5}

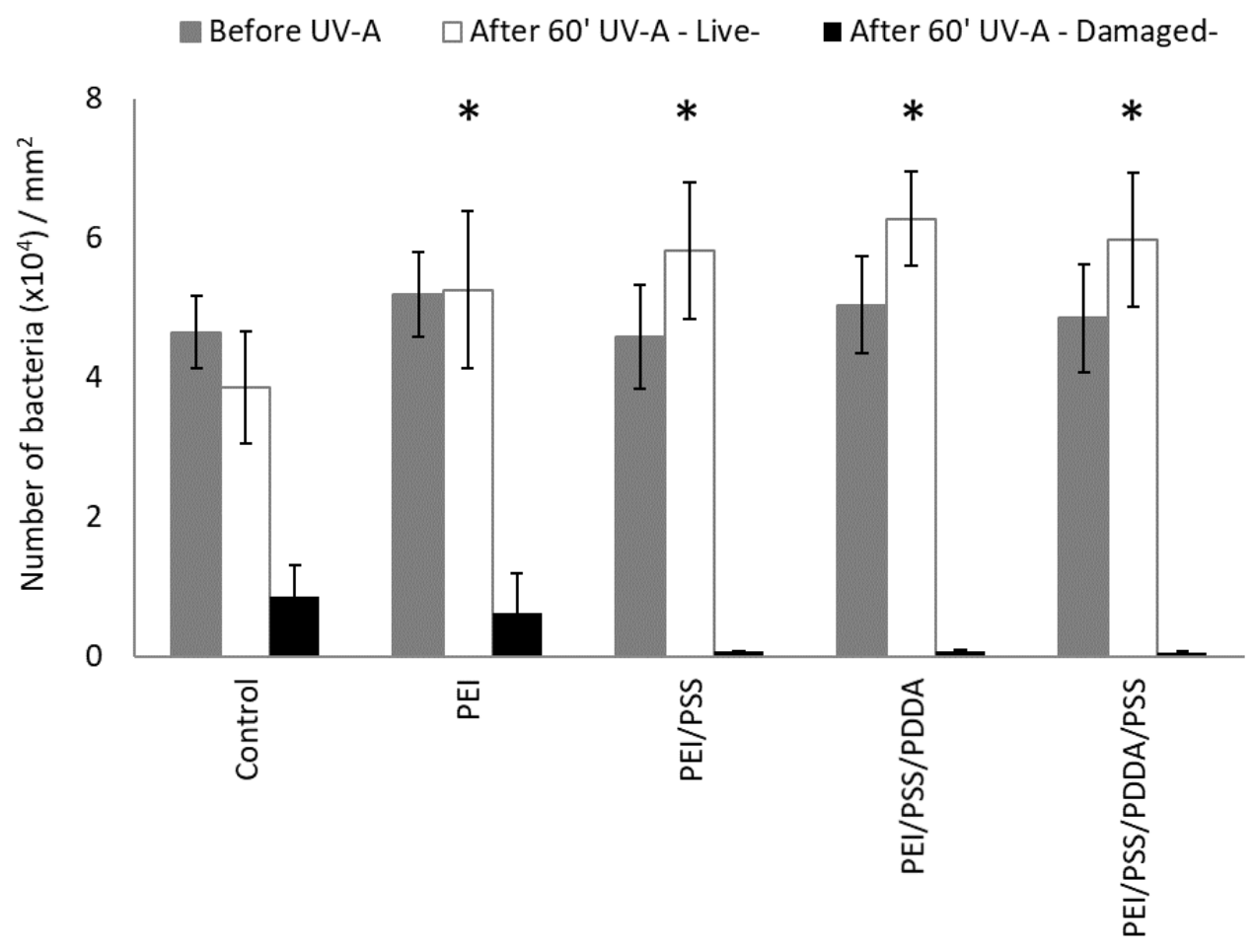

Figure S5: Number of adhered E. coli bacteria on control (silicon wafer) and reference films without $\mathrm{TiO}_{2}$ (PEI, PEI/PSS, PEI/PSS/PDDA, PEI/PSS/PDDA/PSS) before (total population of bacteria) and after ("live" and "damaged" bacteria) $60 \mathrm{~min}$ UV-A irradiation (irradiance of $3 \mathrm{~mW} / \mathrm{cm}^{2}$. Films were built on $2 \mathrm{~cm}^{2}$ silicon wafers. *: significant difference in live quantity compared to control $(p$-value $<$ $0.05)$.

Bacterial assays were performed on control samples in order to remove any possibility of biocidal properties from the sample surface and polyelectrolyte. Reference samples were labelled as follow:

- Control: silicon wafer

- PEI

- PEI/PSS

- $\quad$ PEI/PSS/PDDA

- $\quad$ PEI/PSS/PDDA/PSS 
Table S1

\begin{tabular}{ll}
\hline Layer deposited & $\begin{array}{l}\text { Mass of material } \\
\text { deposited }\left(\mathbf{n g} / \mathbf{c m}^{2}\right)\end{array}$ \\
\hline $\mathrm{PEI}$ & 119.6 \\
$\mathrm{PSS} \# 1$ & 201.1 \\
$\mathrm{TiO}_{2} \# 1$ & 6343.9 \\
$\mathrm{PSS} \# 2$ & 527.1 \\
$\mathrm{TiO}_{2} \# 2$ & 9514.4 \\
$\mathrm{PSS} \# 3$ & 1024.2 \\
$\mathrm{TiO}_{2} \# 3$ & 10857.8 \\
$\mathrm{PSS} \# 4$ & 1865.2 \\
$\mathrm{TiO}_{2} \# 4$ & 9989.3 \\
\hline
\end{tabular}

Table S1. Amount of deposited materials on LbL film calculated with QCM-D data from the $3^{\text {rd }}$ overtone. 


\section{Table S2}

Evolution of the multilayer film thickness after being immerged in a $9 \mathrm{~g} / \mathrm{l} \mathrm{NaCl}$ solution, obtained by ellipsometry

\begin{tabular}{lll}
\hline Samples & Estimated thickness $(\mathbf{n m})$ & Estimated thickness $(\mathbf{n m})$ \\
& $\mathbf{T}=\mathbf{0} \mathbf{h}$ & $\mathbf{T}=\mathbf{1 5} \mathbf{~ h}$ \\
\hline $\mathrm{PEI} /\left(\mathrm{PSS} / \mathrm{TiO}_{2}\right)_{1}$ & $37.6 \pm 2.8$ & $47.3 \pm 3.9$ \\
$\mathrm{PEI} /\left(\mathrm{PSS} / \mathrm{TiO}_{2}\right)_{4}$ & $140.8 \pm 6.2$ & $154.6 \pm 6.3$ \\
$\mathrm{PEI} /\left(\mathrm{PSS} / \mathrm{TiO}_{2}\right)_{6}$ & $222.9 \pm 8.3$ & $246.3 \pm 4.7$ \\
$\mathrm{PEI} /\left(\mathrm{PSS} / \mathrm{TiO}_{2}\right)_{10}$ & $371.6 \pm 9.0$ & $380.6 \pm 7.8$ \\
\hline
\end{tabular}

Table S2. Evolution of the multilayer film thickness after being immerged in a $9 \mathrm{~g} / 1 \mathrm{NaCl}$ solution, obtained by ellipsometry. The stability of the titania LbL films for bacterial assay was assessed by being immerged in $\mathrm{NaCl}$ solution $(9 \mathrm{~g} / \mathrm{l})$ for $15 \mathrm{~h}$. 


\section{Table S3}

HCOOH conversion obtained on specific architectures of films in comparison to that achieved on the $\mathrm{PEI} /\left(\mathrm{PSS} / \mathrm{TiO}_{2}\right)$ reference film with one single layer pair.

Table S3. HCOOH conversion obtained on specific architectures of films in comparison to that achieved on the $\mathrm{PEI} /\left(\mathrm{PSS} / \mathrm{TiO}_{2}\right)$ reference film with one single layer pair. Potentially active layer is visualized in italic format as $\mathrm{PSS} / \mathrm{TiO}_{2}$. Experimental parameters: $[\mathrm{HCOOH}]=45 \mathrm{ppm}_{\mathrm{v}}$, air flow $=20 \mathrm{~mL} / \mathrm{min}$, speed $=0.7 \mathrm{~cm} / \mathrm{s}, U V-A$ irradiance $=2.5 \mathrm{~mW} \cdot \mathrm{cm}^{-2}$, films built on $36 \mathrm{~cm}^{2}$ Si wafers.

\begin{tabular}{|c|c|c|}
\hline Film name & Architecture specification ${ }^{a}$ & $\begin{array}{l}\text { HCOOH } \\
\text { conversion }(\%)\end{array}$ \\
\hline $\mathrm{PEI} /\left(\mathrm{PSS} / \mathrm{TiO}_{2}\right)$ & $\begin{array}{l}\text { Reference film. } \mathrm{TiO}_{2} \text { as "final } \\
\text { layer" }\end{array}$ & 94 \\
\hline $\mathrm{PEI} / \mathrm{PSS} / \mathrm{TiO}_{2} /(\mathrm{PSS} / \mathrm{PDDA})_{8}$ & $\begin{array}{l}\text { (PSS/PDDA) } 8 \text { built on the top } \\
\text { of the first } \mathrm{PSS} / \mathrm{TiO}_{2} \text { layer pair }\end{array}$ & 19 \\
\hline $\mathrm{PEI} / \mathrm{PSS} / \mathrm{TiO}_{2} /(\mathrm{PSS} / \mathrm{PDDA})_{8} / \mathrm{PSS} / \mathrm{TiO}_{2}$ & $\begin{array}{l}\text { (PSS/PDDA })_{8} \text { deposited } \\
\text { between two } \mathrm{PSS} / \mathrm{TiO}_{2} \text { layer } \\
\text { pairs. } \mathrm{TiO}_{2} \text { as "final layer" }\end{array}$ & 32 \\
\hline $\mathrm{PEI} /(\mathrm{PSS} / \mathrm{PDDA})_{8} / \mathrm{PSS} \mathrm{TiO}_{2}$ & $\begin{array}{l}\mathrm{PSS} / \mathrm{TiO}_{2} \text { layer pair built on } \\
\text { the top of the (PSS/PDDA) } \\
\text { layer pairs. } \mathrm{TiO}_{2} \text { as "final } \\
\text { layer" }\end{array}$ & 27 \\
\hline
\end{tabular}

${ }^{a}$ Additional (PSS/PDDA) 8 polyelectrolyte layer pairs were constructed using negativelycharged PSS ( $1 \mathrm{~g} / 1$ at $\mathrm{pH} \quad 2,5$ adjusted by $\left.\mathrm{HNO}_{3}\right)$ and positively-charged poly(diallyldimethyliammonium chloride) (PDDA, $1 \mathrm{~g} / 1$ with $0.5 \mathrm{M}$ of sodium chloride) by the dipping LbL process, using the $\mathrm{PEI} /\left(\mathrm{PSS} / \mathrm{TiO}_{2}\right)_{\mathrm{n}}$ film dipping parameters. The (PSS/PDDA $)_{8}$ layers had an average thickness of $20 \mathrm{~nm}$ determined by ellipsometry. 